Journal of Educational

and Psychological Sciences

Volume (5), Issue (42): 30 Nov 2021

P: 136 - 154

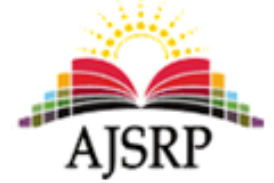

ISSN: 2522-3399

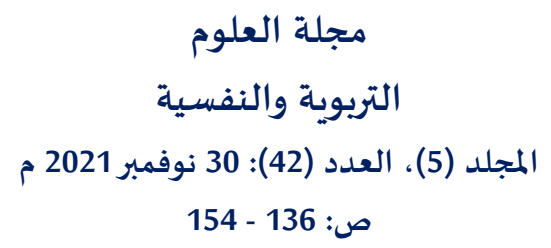

ص: 136

\title{
Evaluation of Teaching Performance of Mathematics Teachers in Thamar Schools in Yemen during the War in light of the effective Teacher Evaluation Model for (Marzano)
}

\section{Zaid Ahmad Nasser Alhadoor}

Center of Academic Development and Quality Assurance || Thamar University || Yemen

\begin{abstract}
The present research aimed at evaluating the teaching performance of Mathematics teachers in Thamar city schools in Yemen during the war in light of the effective teacher evaluation model for (Marzano). To achieve this aim, the descriptive approach was employed, and a note-card was developed based on the criteria and indicators of the special strategies and behavior originating from the effective evaluation model for teacher developed by (Marzano). This card consisted of (41) indicators distributed on three sections, and it was applied to a cluster-random sampling on (64) Mathematics teachers in Thamar primary and secondary schools. The study results revealed that the overall performance of participants was on average. Similarly, the results revealed that the level of performance of the participants in both routine skills and immediate skills was on average. However, the results showed that there was a low level of performance in skills pertinent to the content. The study results showed statistically significant differences in the level of teaching performance of Mathematics teachers for the variable (type the school) and in favor of private school teachers. The study results also showed that there were statistically significant differences in the level of teaching performance of Mathematics teachers for the variable (gender), in favor of the female teachers. In addition, the study results showed that there were statistically significant differences in the level of teaching performance of Mathematics teachers for the variable (years of experience) and in favor of teachers whose experience is less than (5) years, and those whose experiences ranged between (5-10) years, compared to teachers whose experiences were more than (10) years of experience, Conducting professional development courses for mathematics teachers in accordance with the criteria of effective teacher evaluation, neutralizing educational institutions from war and disbursing teachers' salaries.
\end{abstract}

Keywords: teaching performance- mathematics teachers- the war- Marzano's effective teacher assessment model.

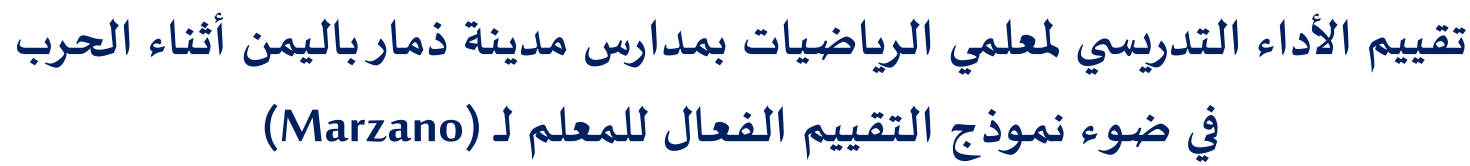

\author{
زيد أحمد ناصر أحمد الهدور \\ مركز التطوير الأكاديمي وضمان الجودة || جامعة ذمار|| اليمن
}

المستخلص: هدفت الدراسة الحالي إلى تقييم الأداء التدريسي لمعلمي الرياضيات بمدارس مدينة ذمار باليمن أثناء الحرب في ضوء نموذج التقييم الفعال للمعلم لـ (Marzano)، ولتحقيق هذا الهدف تم استخدام المنهج الوصيفي، وتم إعداد بطاقة ملاحظة بناءً على معايير

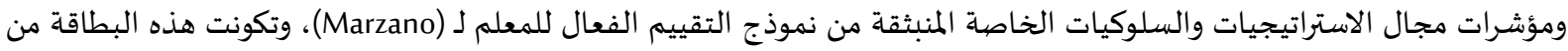

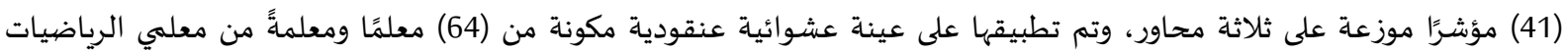


بمدارس مدينة ذمار الأساسية والثانوية، وأظهرت نتائج الدراسة أن مستوى الأداء التدريسي الكلي لأفراد عينة الدراسة (متوسط)، فكان

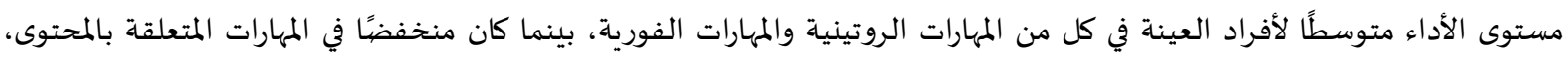

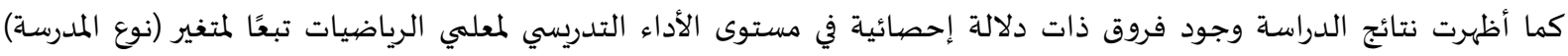

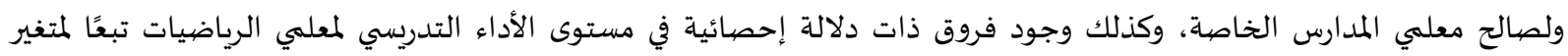

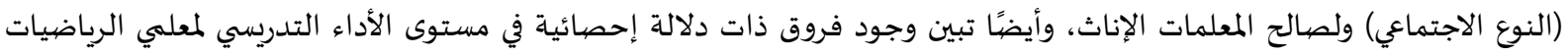

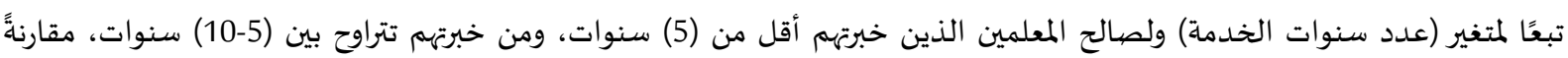

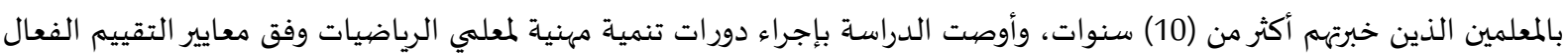

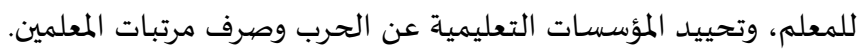
الكلمات المفتاحية: تقييم الأداء التدريسي - معلمو الرياضيات - الحرب- نموذج التقييم الفعال للمعلم لـ (Marzano).

المقدمة.

يقاس تطور المجتمعات بمدى اهتمامها بمؤسسات التعليم، ويعد المعلم أحد العناصر المهمة والأسـاسية لنجاح العملية التعليمية في مؤسسات التعليم، وبذلك فإن المعلم أصبح أساس التنمية والمستقبل الزاهر للبلدان، المانه

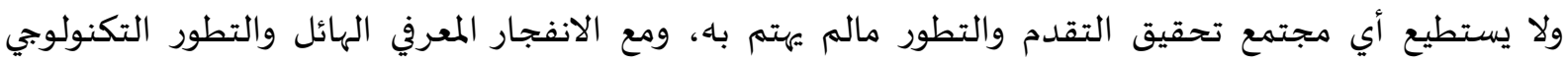

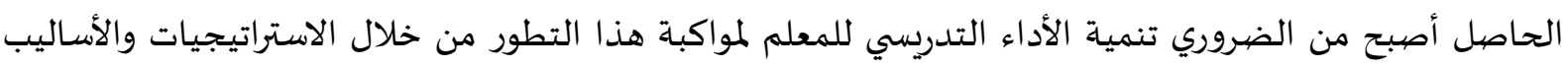
الحديثة في مجالات التعليم المختلفة.

ومازال التدريس المتمركز حول المعلم هو السائد اليوم، وكذا ممارسة طرائق التدريس التقليدية التي تركز

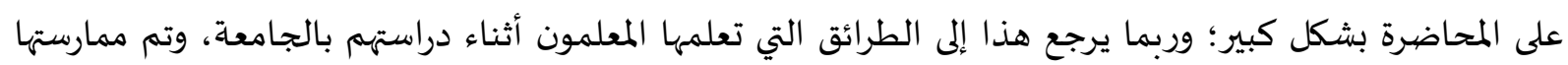

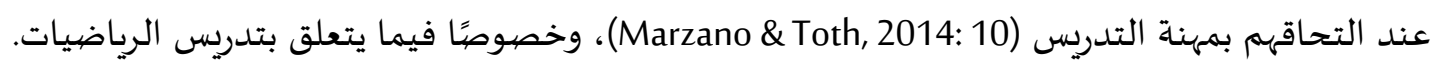

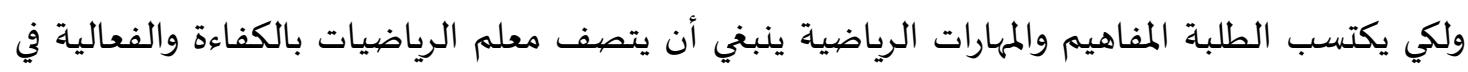
قدرته على التدريس، وإكساب الطلبة المفاهيم الرياضية السليمة، وإحداث تغيرات مرغوبة في سلوك الطلبة البات، وهذا

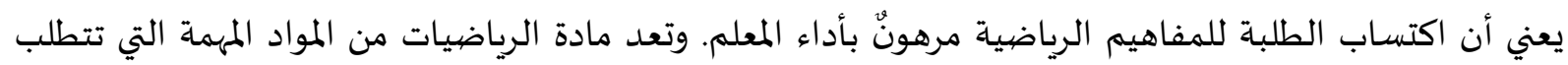

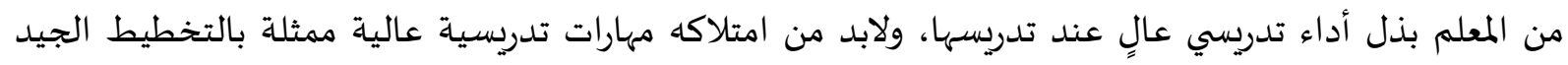
لدروس الرياضيات، واختيار أفضل الاستراتيجيات والأساليب والتقنيات الحديثة لتنفيذ التدريس (الخزيم، 2019، مئل ص. 159).

ومن الضرورة أن يستند تدريس الرياضيات وبرامج التدربب لمعلمي الرياضيات على معايير مهنية معاصرة،

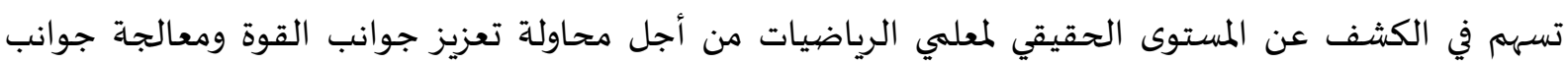

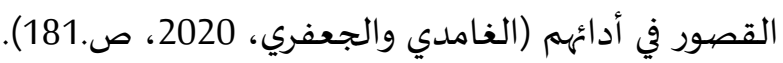

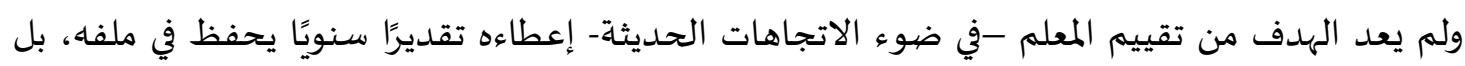
محاولة للتعرف على نواحي القوة والضعف في عملية التدريس للكشف عن حقيقة التأثير الفعلي للمعلم في العملية

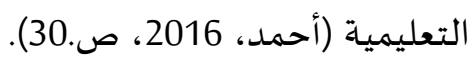
وقد تم تصميم نماذج لتقييم المعلم بغرض مساعدة المسؤولين للتمييز بين مستويات أداء المعلمين بإنصاف

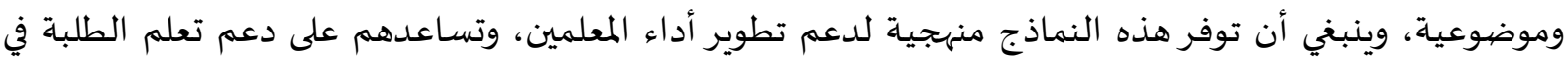

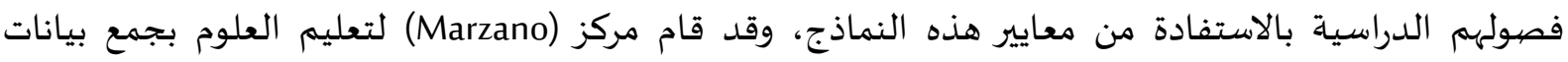

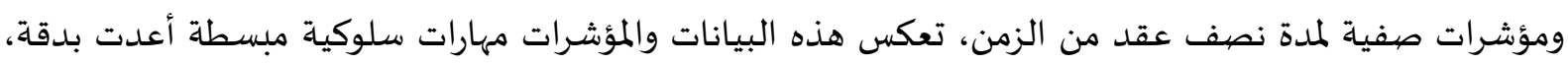


لكي تكون الأكثر استخدامًا لتحقيق دعم التطوير المهني ونمو تعلم الطلبة، ولتصبح عملية الإشراف والتوجيه على المعلمين أكثر دقة (Carbaugh et al., 2017, P.4). ويعتبر نموذج (Marzano) نموذجًا حديثًا لتطوير أداء المعلم، وتنمية تحصيل الطلبة، ويساعد في تدريب

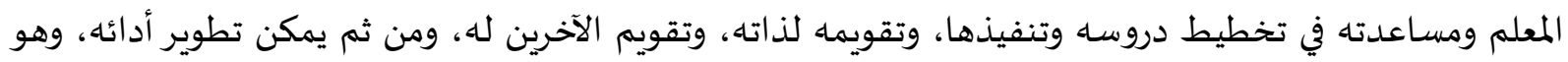

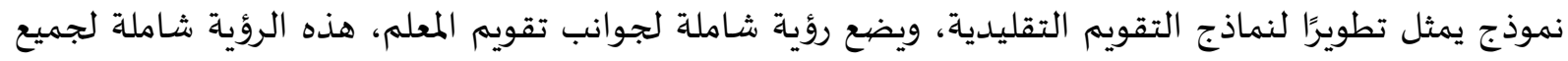

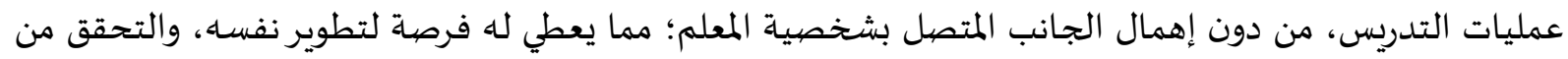

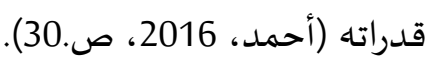

ويعد نموذج تقييم المعلم الفعال أداة مفضلة للموجه والمعلم، فهو يستخدم إجراءات منظمة ذات ذات منهجية

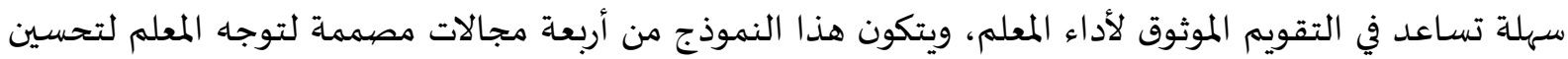

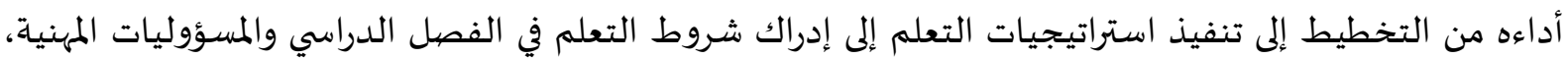
ولا يقتصر على استخدام المعلم لاستراتيجيات التعلم فحسب، بل يساعده في مراقبة وتتبع نمو التعلم من خلال أدلة

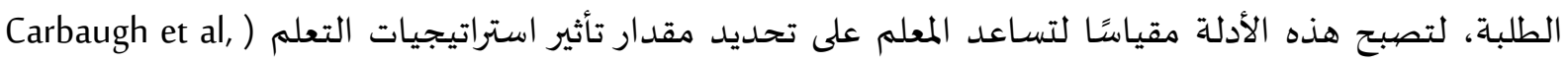

ويتضمن نموذج التقييم الفعال للمعلم لـ (Marzano) عدة مؤشرات موزعة على الأربعة المجالات، هذه المؤشرات تعطي المعلمين فرصة للتفكير في تطوير أدائهم التدريسي وتوجه جهودهم إلى العوامل التي تؤثر على تعلم طلبتهم، وهذا جانب فريد تضمنه هذا النموذج (Eller \& Eller, 2015, p. 23).

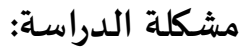

لا يزال المعلمون يفتقرون إلى نموذج للتطوير المهني ذي معايير واضحة لتنمية أدائهم التدريسي؛ لمواكبة

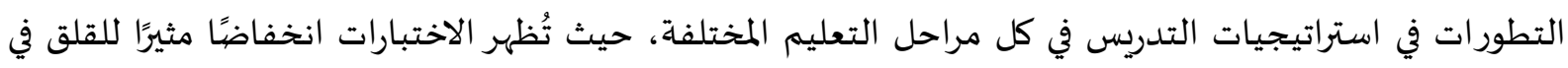

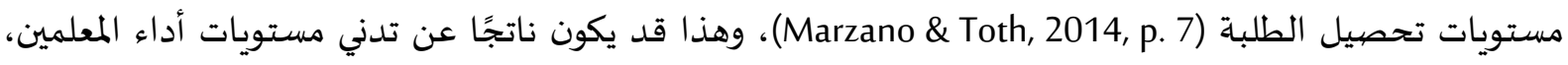

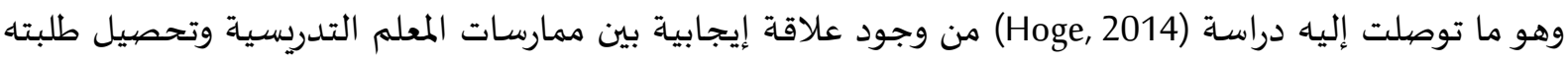

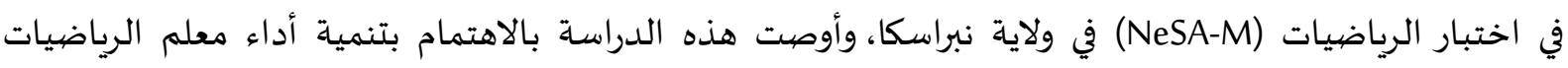
والذي أصبح ضروريًا لتحسين تعلم الطلبة.

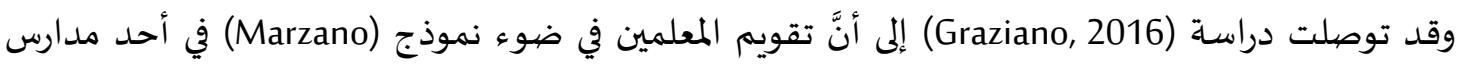
الثانوية بولاية نيوجرسي حسنت ممارساتهم لتلك المهارات المتضمنة في النموذج وكذلك أثرت إيجابًا في مستوى إنجازات طلبتهم.

وتوصلت نتائج دراسة (Tetzlaff, 2018) إلى أنَّ (20.2\%) من مديري مدارس ثانوية في مينيسوتا من عينة

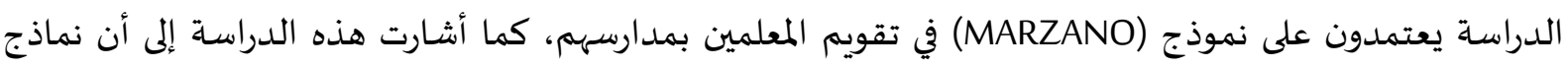
تقويم المعلمين تؤدي إلى تحسين أدائهم. وقد أبرزت دراسة (Smith, 2018) أهمية تعزيز النمو المهني للمعلمين من خلال تقييم المعلم ودعم مشاركته

في دورات التنمية المهنية، ودعت هذه الدراسة إلى الاهتمام بتقييم المعلم وإبعاده عن الاختلافات السياسة.

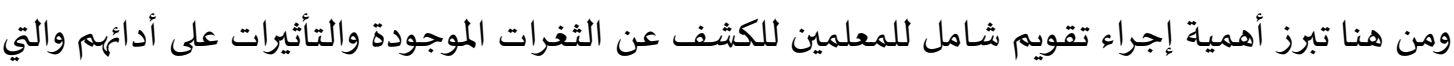

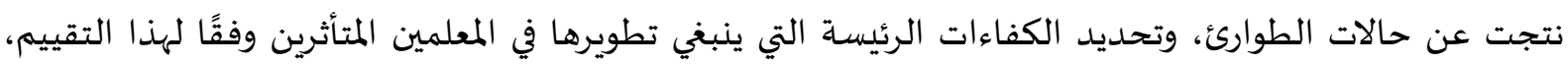


كما ينبغي تزويد المعلمين بالمعرفة الملائمة والمهارات اللازمة لمواجهة الأزمات المستقبلية من أجل رفع مستوى الجاهزية

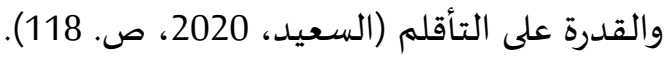
Inter-Agency Network for Education in ) وقد دعت الشبكة المشتركة لوكالات التعليم في حالات الطوارئ بإجراء تقييم كفاءة المعلمين في حالات الطوارئ، وبصورة دورية لتحسين أدائهم، وتطوير (Emergencie "INEE", 2014 معايير لدعم ملاحظة أدائهم وتقييما (ص. 102). ومن الملاحظ بأن التعليم في اليمن يواجه تحديات كثيرة، منها التوزيع غير العادل للمعلمين، ورداءة مستوى

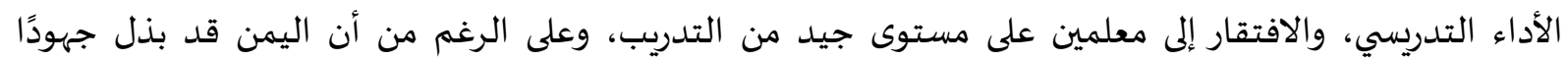

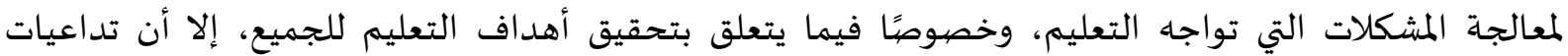

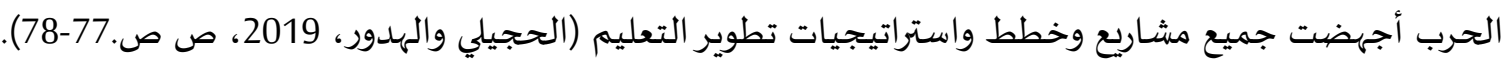

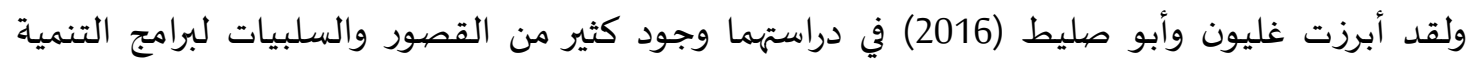

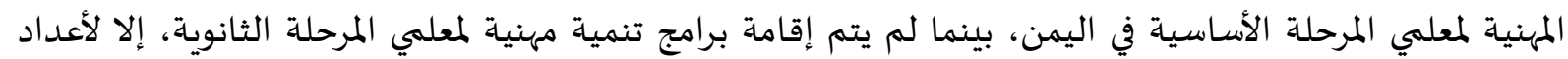

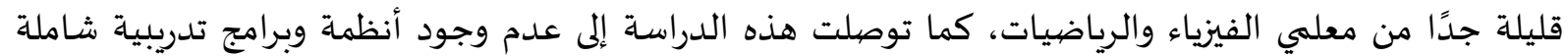
تعم المحافظات اليمنية. وقد أورد تقرير مكتب تنسيق الشؤون الإنسانية (2021) أن مشكلة نقص المعلمين في اليمن تنتشر في

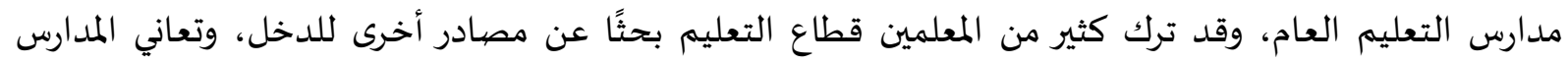

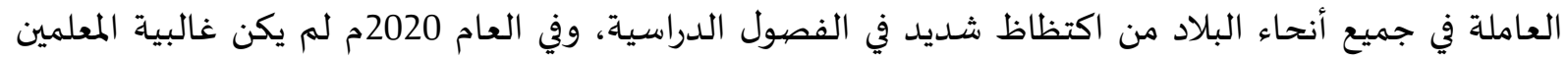
يتقاضون رواتههم في (11) محافظة، ويشكل هؤلاء المعلمين ما يقرب من (64\%) من المعلمئمين باء باليمن، ويعتبر التأخير

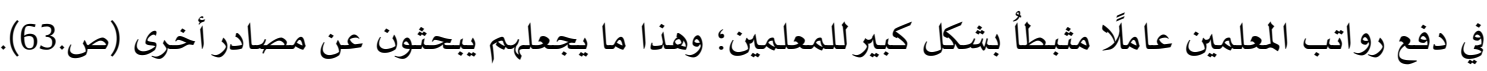

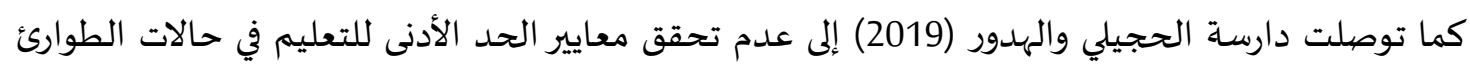

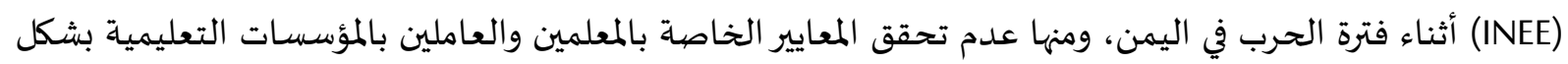

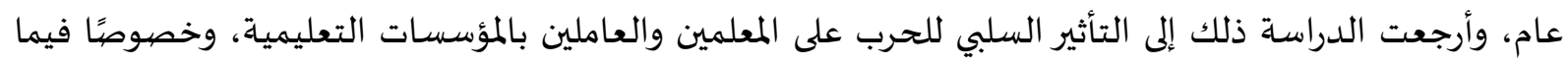

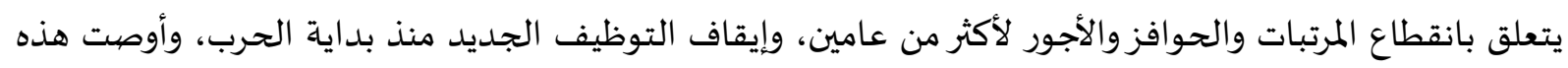

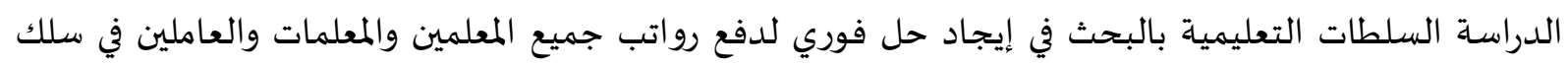
التعليم، وإجراء دراسات للتعرف على حجم الأضرار التي لحقت بمؤسسات التعليم جراء الحرب. وقد توصلت دراستا لحمر (2002) وسفيان (2009) إلى تدني مستويات أداء معلمي المرحلة الأساسية باليمن.

وتوصلت دراسة علي (2016) إلى مستوى أداء متوسط لمعلمي الرياضيات بالمرحلة الثانوية باليمن في ضوء المعايير المهنية، وكذلك عدم وجود فروق في متوسطات أداء معلمي الرياضيات تعزى لمتغيري الجنس وعدد سنوسوات الخدمة.

وأوصت دراسة الشراعي (2006) بتقييم الأداء التدريس لمعلمي الرياضيات في مدارس التعليم العام باليمن

$$
\text { في ضوء الاتجاهات الحديثة لتدريس الرياضيات. }
$$

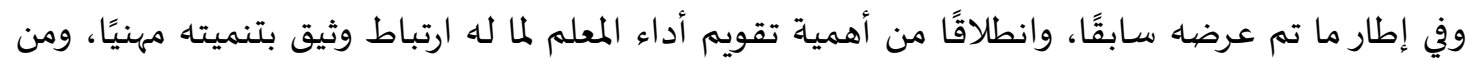

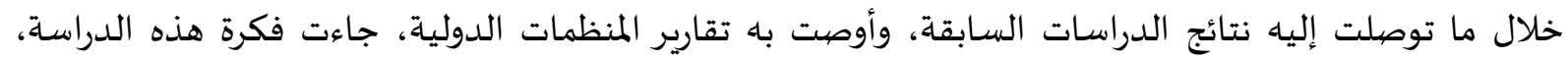

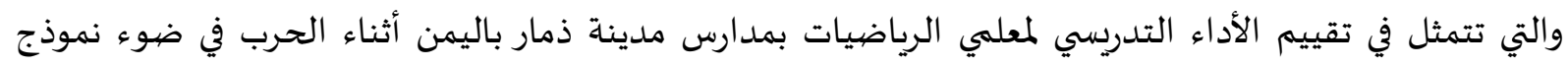

التقييم الفعال للمعلم لـ (Marzano). 


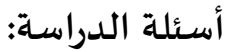

يمكن تحديد مشكلة هذه الدراسة في السؤالين الآتيين:

1- ما مستوى الأداء التدريسي لمعلمي الرياضيات بمدارس مدينة ذمار باليمن أثناء الحرب في ضيوء

الاستراتيجيات والسلوكيات الخاصة المنبثقة من نموذج التقييم الفعال للمعلم لـ (Marzano)؟

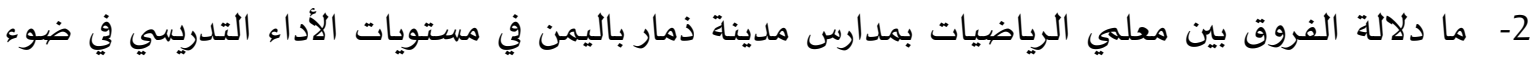

الاستراتيجيات والسلوكيات الخاصة المنبثقة من نموذج التقييم الفعال للمعلم لـ (Marzano) وفقًا للمتغيرات

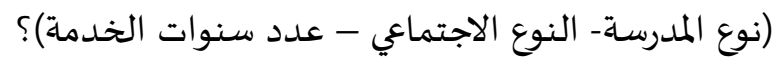

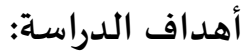

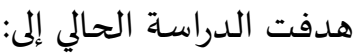

1- تقييم الأداء التدريسي لمعلمي الرياضيات بمدارس مدينة ذمار باليمن أثناء الحرب في ضوء نموذج التقييم

الفعال للمعلم لـ (Marzano) كهدف رئيس ولتحقيق هذا الهدف تم اشتقاق هدفين فرعيين هما:

2- الكشف عن مستوى الأداء التدريسي لمعلمي الرياضيات بمدارس مدينة ذمار باليمن أثناء الحرب في ضوء

الاستراتيجيات والسلوكيات الخاصة المنبثقة من نموذج التقييم الفعال للمعلم لـ (Marzano)؟

3- التعرف إلى دلالة الفروق بين معلمي الرياضيات بمدارس مدينة ذمار باليمن في مستويات الأداء التدرسيي في

ضوء الاستراتيجيات والسلوكيات الخاصة المنبثقة من نموذج التقييم الفعال للمعلم لـ (Marzano) وفقًا

$$
\text { للمتغيرات (نوع المدرسة- النوع الاجتماعي - عدد سنوات السات الخداتهة). }
$$

أهمية الدراسـة:

تمثلت أهمية الدراسة في الآتي:

1. تقديم تغذية راجعة لمعلمي الرياضيات بمدارس مدينة ذمار حول واقع أدائهم التدرسي والكشف عن أوجه

القوة والضعف فياه.

2. يزود المسؤولين ومتخذي القرار بمكتب التربية والتعليم بذمار بالاحتياجات التدربيية لمعلمي الرياضيات

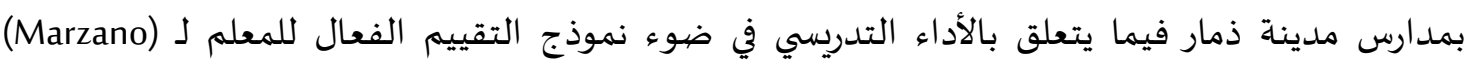

وخصوصًا أثناء فترة الحرب.

3. يزود الموجهين ببطاقة ملاحظة للاستفادة منها عند تقييم الأداء التدريسي لمعلمي الرياضيات.

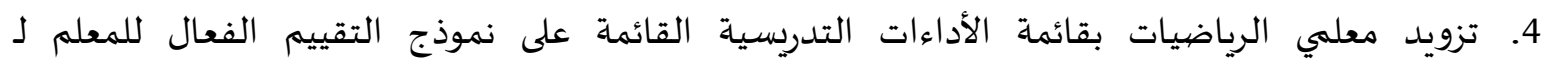

لتقويم وتطوير أدائهم التدريسي الفعال ذاتيًا.

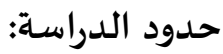

تقتصر هذه الدراسة على الحدود الآتياة:

الحدود الموضوعية: تقييم الأداء التدريسي لمعلمي الرياضيات بمدارس مدهدية مدينة ذمار باليمن أثناء الحرب في ضوء

مجال الاستراتيجيات والسلوكيات الخاصة المنبثقة من نموذج التقييم الفعال للمعلم لـ (Marzano).

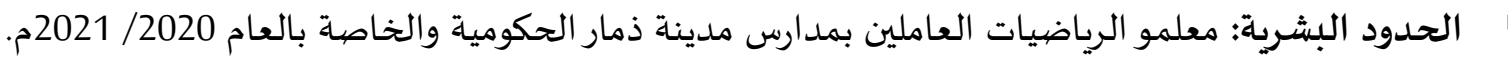

الحدود المكانية: مدارس مدينة ذمار الأساسية والثانوية، الحكومية والخاصية.

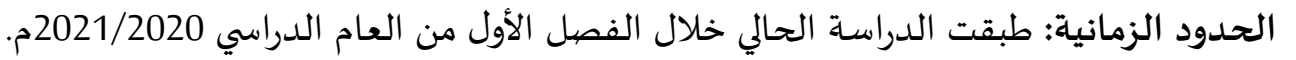


- التقييم: هو عملية تقرير قيمة الشيء أو كميته بهدف إلى الحكم الموضوعي على العمل المقوم، صلاحًا وفسادًا،

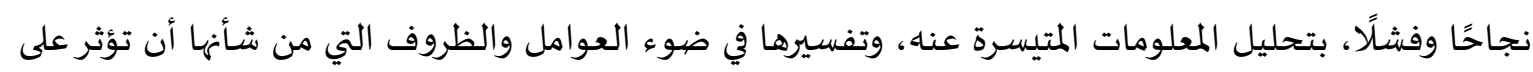

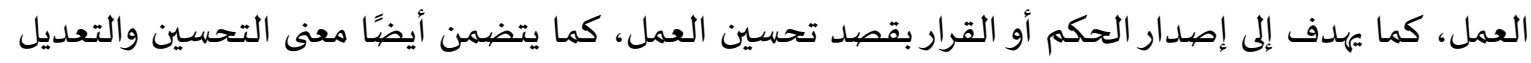

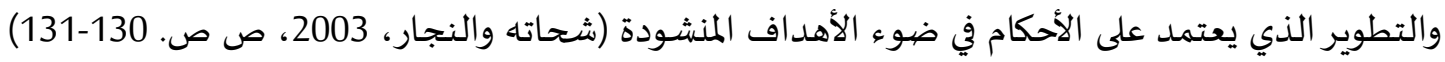

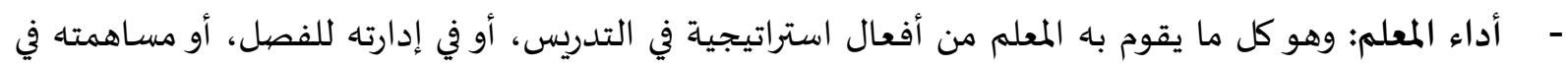

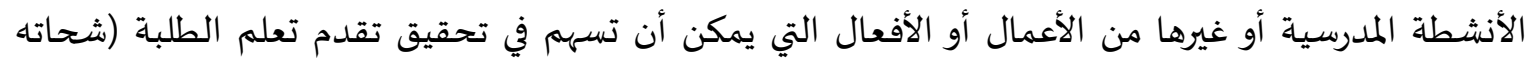

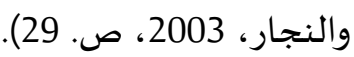

O ويُعرف إجرائيًا بأنه: مجموعة من السلوكيات والإجراءات والنشاطات والمهارات التي يقوم بها معلم الرياضيات

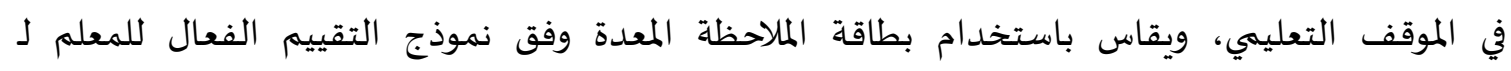

(Marzano)

- تقييم أداء المعلم: إصدار الحكم على مدى كفاءة المعلم في تنفيذ عملية التدريس، وتحقيق أهدافها، وتحديد

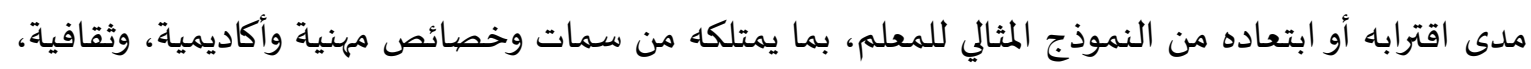

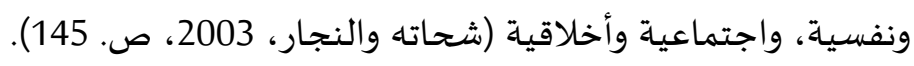

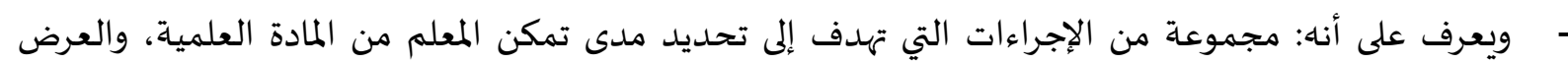

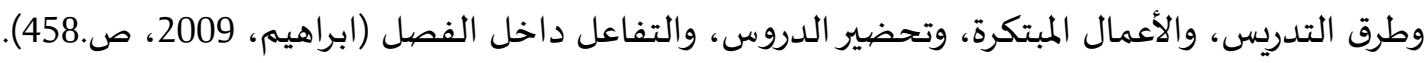

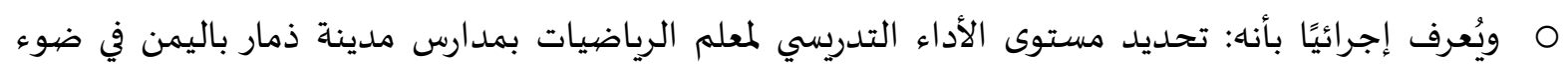

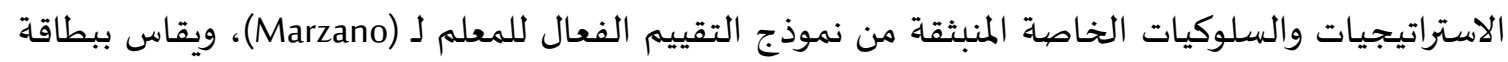

الملاحظة المعدة لذلك.

نموذج التقييم الفعال للمعلم لـ (Marzano): هو نموذج مكون من معايير عدة لتقويم أداء المعلم، تم إصداره

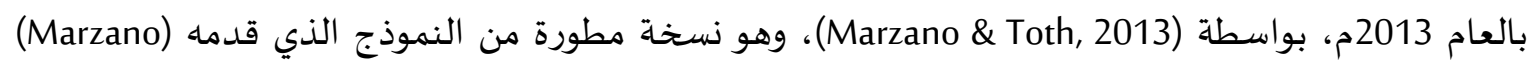

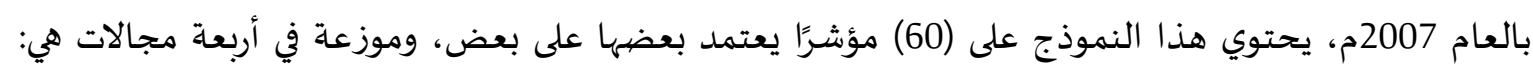

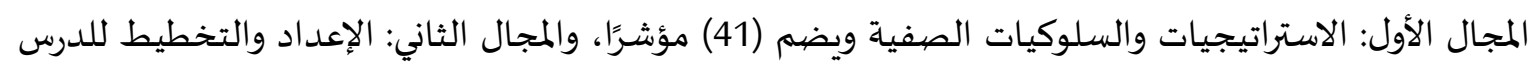

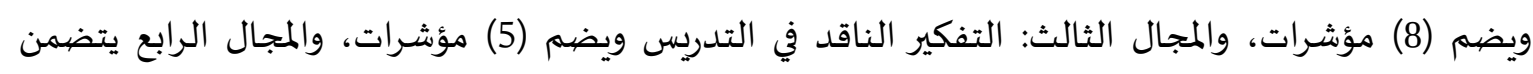
الزمالة والمهنة ويضيم (6) مؤشرات (Marchant et al, 2015, p. 96). - الحرب: ويقصد باه النزاع المسلح الحاصل باليمن منذ العام (2015) وحتى الوقت الحماضر. 2. 2 الإطار النظري للدراسـة.

نموذج التقييم الفعال للمعلم لـ (Marzano): يعد نموذج (Mrzano) لتقييم المعلم أحد الأساليب التي يمكن للمعلمين من خلالها تحسين أدائهم

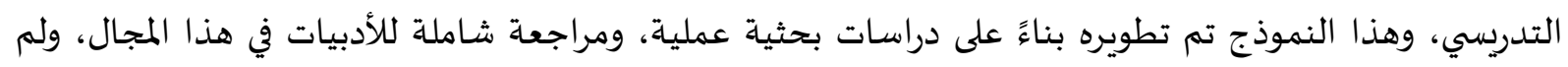

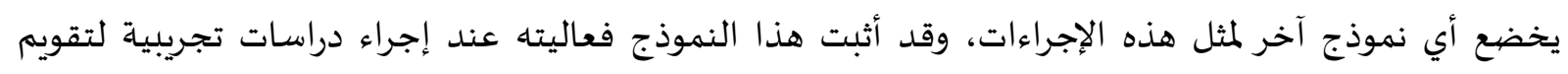

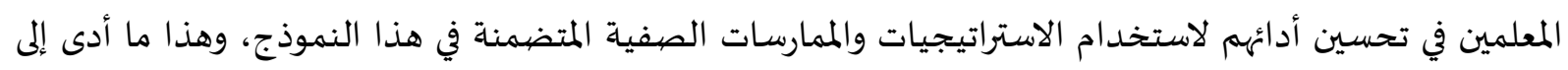
زيادة مستوى التحصيل العلمي لدى طلبتهم بنسبة (16\%)، وعلاوة على ذلك يعمل هذا النموذج على التطوير الممني 
للمعلمين من خلال التطوير الذاتي، والتطوير عبر الاستفادة من الأقران فقد يستخدم المعلمون هذا النموذج بشكل مستقل أو مع زملائهم لتنمية خبراتهم الصفية من خلال الممارسة للنموذج (

ويتضمن نموذج التقييم الفعال للمعلم لـ (Marzano) مجموعة محددة من ممارسات المعلمين، وهي ترتبط

ارتباطًا مباشرًا بأداء الطالب (Tetzlaff, 2018, p.15).

ويهدف هذا النموذج إلى سد الفجوة بين تقييم المعلم والتحصيل العلهي للطلبة، وهو خلاصة ما يقرب من

خمسة عقود من الدراسات حول التعليم الفعال والممارسات التعليمية، والغرض من هذا النموذج مساعدة المعلمين

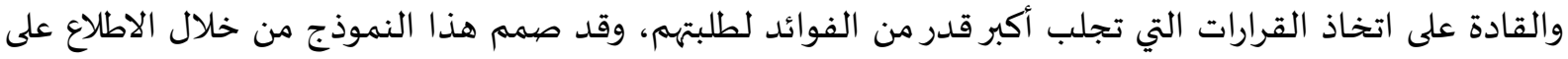
الكثير من الدراسات التاريخية والبحوث المعاصرة، لتقديم نظرة أكثر شمولًا عن فعالية المعلمين (الأحمري والصمداني، ص245).

ولقد وضع (Mrzano) في نموذجه لتقييم المعلم تسعة أسئلة أساسية تساعد المعلمين في تطوير أدائهم

التدريسي وتؤثر على تعلم الطلبة، هذه الأسئلة وردت في تقرير مركز (Marzano) لتعليم العلوم ( Learning Sciences)

Marzano Center, 2013, p.3

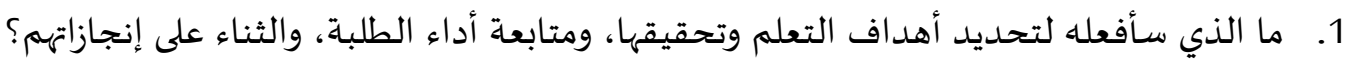

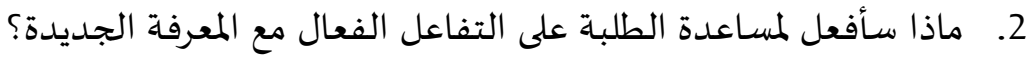

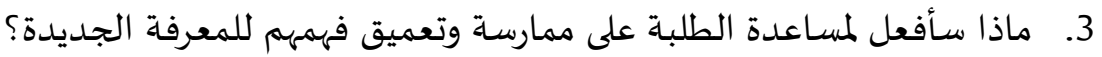

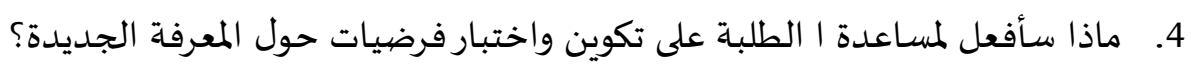

5. ماذا سأفعل لتفعيل مشاركة الطلبة؟ مأباعل

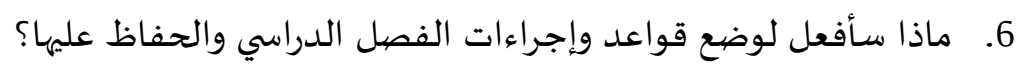

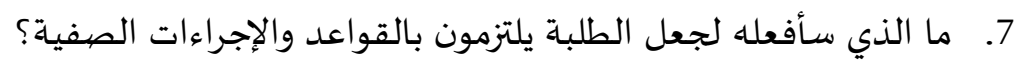

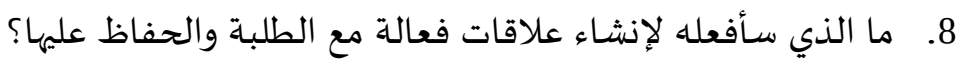

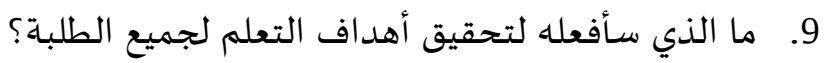

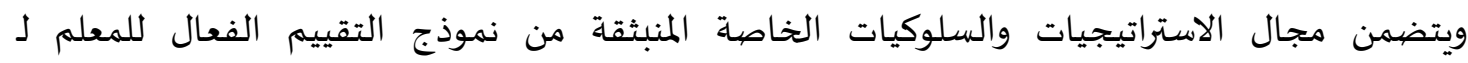

(41) (Marzano)

وردت في (Marzano et al, 2014, p.10):

$$
\text { المحور الأول: المهارات الروتينية. }
$$

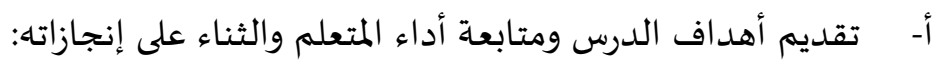

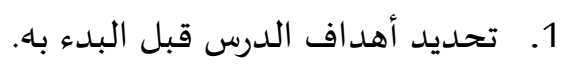$$
\text { 2. - 2. - تقويم أداء الطلبة. }
$$$$
\text { 3. استخدام أساليب التعزيزوالثناء. }
$$

ب- وضع القواعد والإجراءات والحفاظ عليها:

1. وضع خطة إجرائية لتنفيذ الدرس.

2. تنظيم الصف الدراسي بالشكل الذي يسهل سير العملية التعليمية.

$$
\text { المحور الثاني: المهارات المتعلقة بالمحتوى. }
$$

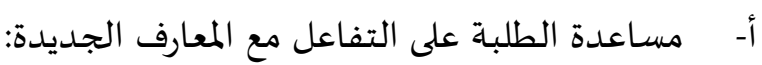




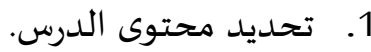

$$
\begin{aligned}
& \text { 2. ت تنظيم الطلبة للتفاعل مع المعرفة الجديدة. } \\
& \text { 3. تقديم محتوى المعرفة الجديدة. } \\
& \text { 4. تقسيم المحتوى إلى أجزاء مفهومة. } \\
& \text { 5. اشراك الطلبة في معالجة المعلومات الجديدة. } \\
& \text { 6. مساعدة الطلبة على التوسع في المحتوى الجديد. } \\
& \text { 7. مساعدة الطلبة على كتابة المعرفة الجديدة وتمثيلها. } \\
& \text { 8. مساعدة الطلبة على نقد تعلمهم. }
\end{aligned}
$$

ب- مساعدة الطلبة على ممارسة المعرفة الجديدة وتعميق فهمهم لها:

1. 1 استعراض المحتوى السابق مع الطلبة.

2. ت تنظيم الطلبة لممارسة المعرفة واستيعابها.

3. تكليف الطلبة بواجبات المنزلية.

4. اشراك الطلبة في الأنشطة التي تتطلب منهم دراسـة أوجاه التشابه والاختلاف.

5. مساعدة الطلبة على اكتشاف الأخطاء الناشئة في تفكيرهم.

6. مساعدة الطلبة على ممارسة المهارات والاستراتيجيات والعمليات المناسبة.

7. مساعدة الطلبة على مراجعة وتصحيح معارفهه.

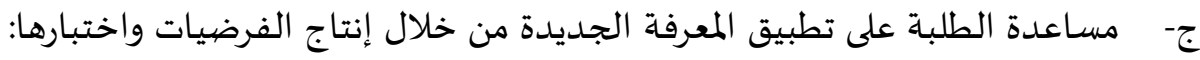

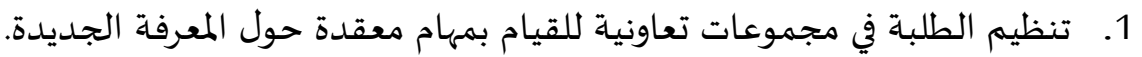

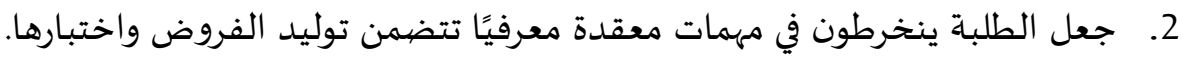

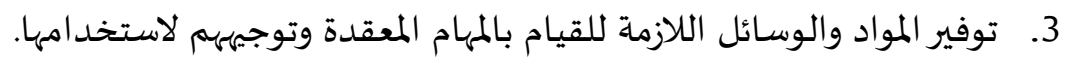

المحور الثالث: المهارات الفورية:

أ- العمل على تفعيل مشاركة الطلبة:

1. - متابعة مستوى مشاركة الطلبة.

2. استخدام الألعاب التعليمية.

3. تنظيم عملية الحواروالمناقشة.

4. السماح باستخدام التحركات البدنية للطلبة.

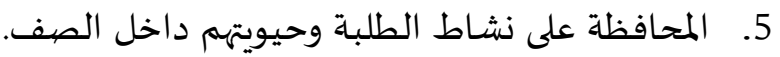

6. اظهار الحماس أثناء الدرس.

7. - استخدام الحوار الودي مع الطلبة.

8.

9. تقديم معلومات غير مألوفة أو مثيرة لاهتمام الطلبة.

ب- الالتزام بالقواعد والإجراءات الصفيماتة:

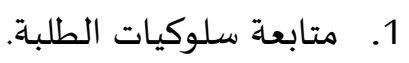

2. تطبيق عقوبات عند رفض الطلبة الامتثال للقواعد والإجراءات الصفية.

3. توجياء الطلبة بالالتزام بالقواعد والإجراءات الصفية. 
ج- العمل على إنشاء علاقات فعالة مع الطلبة:

1. اتركيز على اهتمامات الطلبة وخلفياتهم.

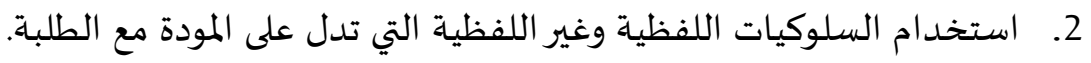

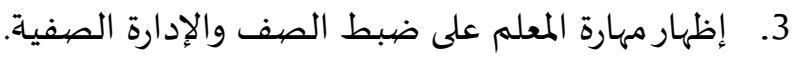

د- الاهتمام بجميع فئات الطلبة من حيث الأداء:

1. إظهار التقدير والاهتمام بالطلبة منخفضي الأداء.

2. طرح الأسئلة على الطلبة منخفضي الأداء.

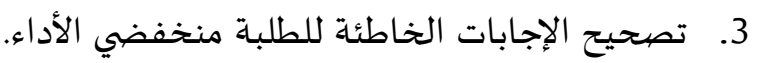

3. منهجية الدراسـة وإجراءاتها.

منهج الدراسة:

لتحقيق أهداف الدراسة تم استخدام المنهج الوصفي، كمنهج يتناسب مع طبيعة مثل هذا النوع من الأبحاث.

مجتمع الدراسة:

تكون مجتمع الدراسـة من جميع معلمي الرياضيات العاملين بمدارس مدينة ذمار بالفصل الأول من العام

الدراسي 2021/2020م، والبالخ عددهم (319) معلمًا ومعلمةً.

عينة الدراسـة:

تكونت عينة الدراسة من (64) معلمًا ومعلمةً من معلمي الرياضيات والعاملين بمدارس مدينة ذمار الأساسية

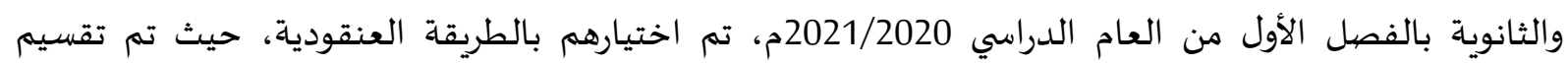

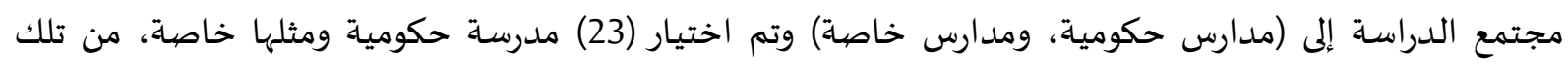

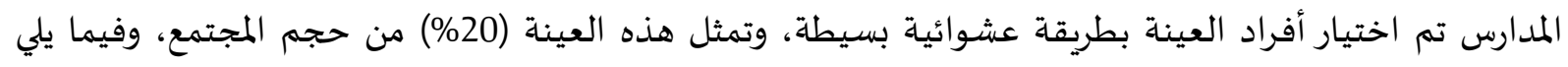

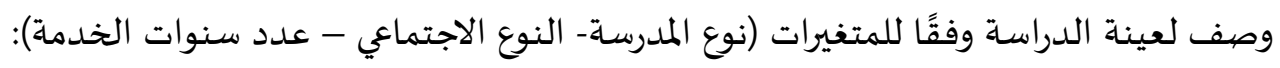

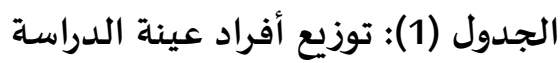

\begin{tabular}{|c|c|c|c|c|c|c|c|}
\hline \multicolumn{2}{|c|}{ المجموع } & \multicolumn{2}{|c|}{ المدارس الخاصية } & \multicolumn{2}{|c|}{ المدارس الحكومية } & \multirow{2}{*}{ الفئة } & \multirow{2}{*}{ المتغير } \\
\hline النسبة \% & العدد & النسبة \% & العدد & النسبة \% & العدد العد & & \\
\hline 54.69 & 35 & 20.00 & 7 & 80.00 & 28 & ذكور & \multirow{2}{*}{ الاجتماعي } \\
\hline 45.31 & 29 & 75.86 & 22 & 24.14 & 7 & إناث & \\
\hline 25.00 & 16 & 87.50 & 14 & 12.50 & 2 & أقل من (5) سـنوات & \multirow{3}{*}{ عدد سـنوات الخدمة } \\
\hline 26.56 & 17 & 70.59 & 12 & 29.41 & 5 & (10-5) سنوات & \\
\hline 48.44 & 31 & 9.68 & 3 & 90.32 & 28 & أكثر من (10) سنوات & \\
\hline \%100 & 64 & 45.31 & 29 & 54.69 & 35 & المجموع & \\
\hline
\end{tabular}


تم ترجمة معايير ومؤشرات مجال الاستراتيجيات والسلوكيات الخاصة المنبثقة من نموذج التقييم الفعال

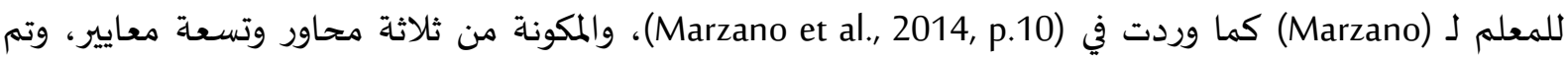

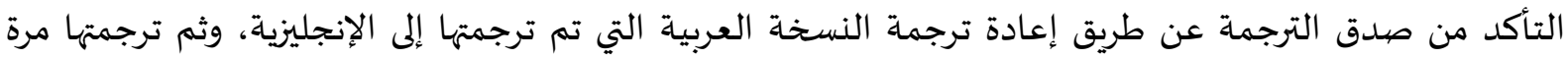

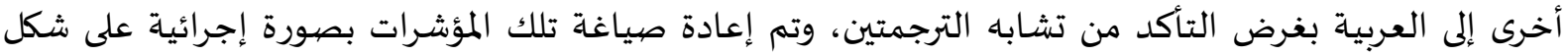

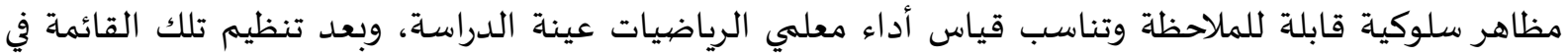
صيغتها الأولية تم عرضها على (5) من المستشارين من أعضاء هيئة التدريس المتخصصين في تعليم الرياضيات من

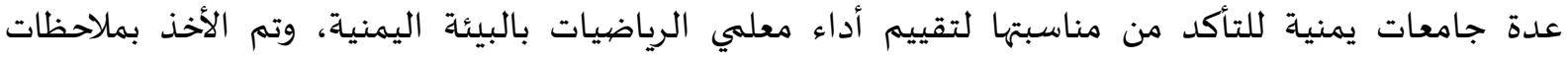

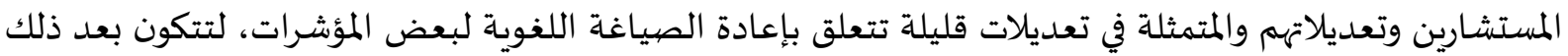

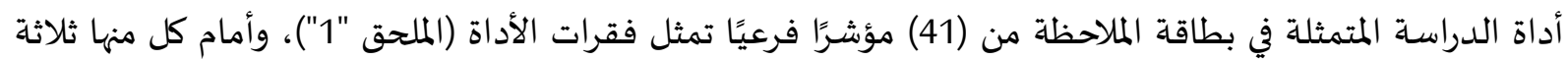
بدائل للاستدلال على أداء المعلمين، وهي (مرتفعة، متوسطة، منخفضية)، وتم توزيع هذه المؤشرات على ثلاثة محاور

1. المهارات الروتينية: وتحتوي على (5) مؤشرات، موزعة على معيارين.

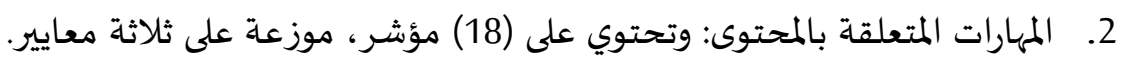

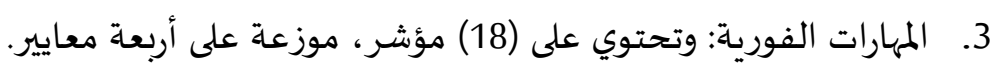

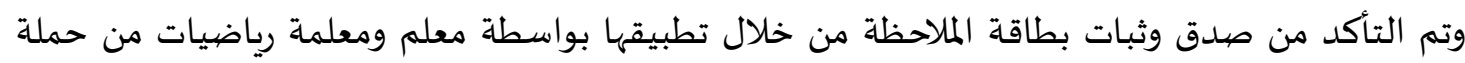

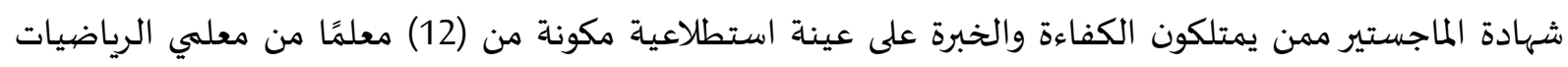

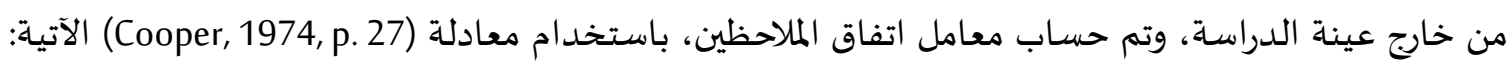

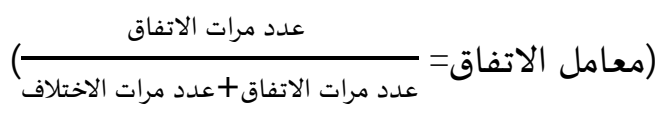

حيث بلغ معامل الاتفاق (0.89) وهذا يدل على صدق بطاقة الملاحظة.

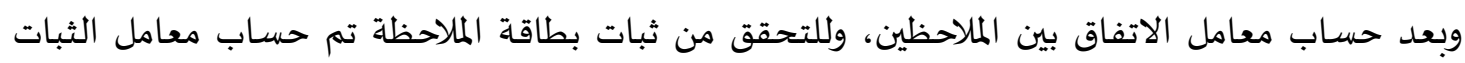

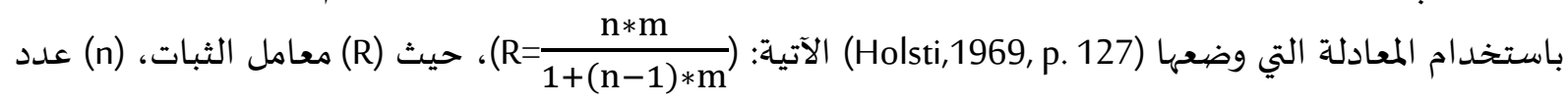
الملاحظين = 2، (m) معامل الاتفاق = (0.89)، وبذلك بلغ معامل الثبات (R) (0.94)، وهذا يعد معامل ثبات مقبول، وذلك يؤدي إلى ضمان الثقة في بطاقة الملاحظة.

إجراءات تطبيق الدراسـة: تمعاء

تم تدريب معلم ومعلمة من معلمي الرياضيات من حملة شهادة الماجستير على إجراء عملية الملاحظة

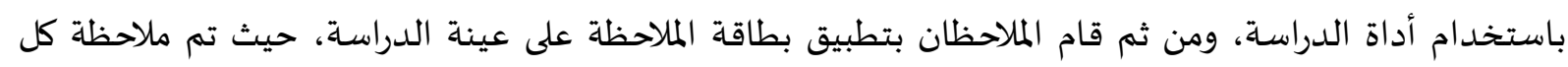
معلم أو معلمة حصتين كاملتين وفي درسين مختلفين، واستغرق تطبيق عملية الملاحظة ثمانية أسابيح.

تفريغ وتحليل البيانات:

تم تفريخ بيانات بطاقة الملاحظة بعد تطبيقها، ومن ثم تحليلها باستخدام البرنامج الإحصائي (SPSS) حيث

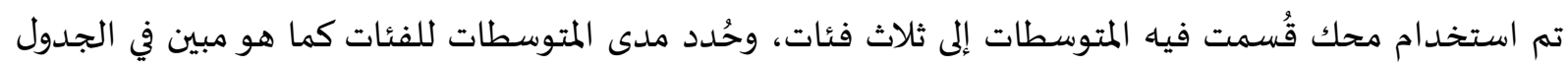


الجدول (2): محكك الحكم لمستوى أداء معلمي الرياضيات حسب المتوسطات الحسابية.

\begin{tabular}{|c|c|c|c|c|}
\hline \multirow{2}{*}{ 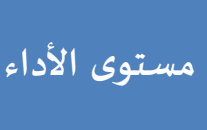 } & \multicolumn{2}{|c|}{ الحدود الحقيقية للمتوسط الحسابي } & \multirow{2}{*}{ قيمة البديل } & \multirow{2}{*}{ درجة التوافر } \\
\hline & 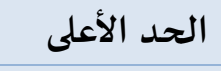 & 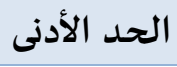 & & \\
\hline مرتفع & 3.00 & 2.34 & 3 & 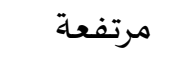 \\
\hline متوسط & 2.33 & 1.67 & 2 & 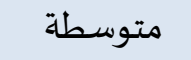 \\
\hline منخفض & 1.66 & 1.00 & 1 & منخفضية \\
\hline
\end{tabular}

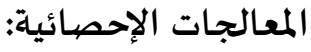

تم معالجة البيانات إحصائياً بواسطة برنامج (SPSS) وتم استخدام الأساليب الآتية: 1

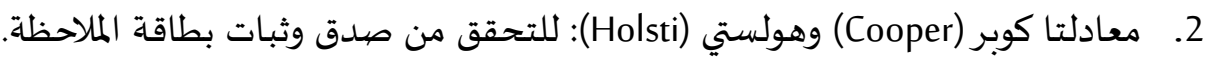

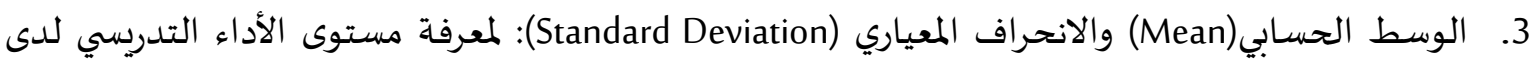
أفراد العينة.

4. الاختبار التائي لعينتين مستقلتين (Independent Samples Test): لإيجاد دلالة الفروق بين معلمي الرياضيات في مستويات الأداء التدريسي وفقًا لمتغيري (نوع المدرسة- النوع الاجتماعي).

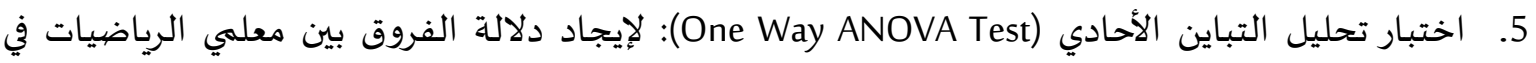

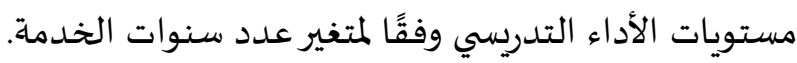
6. اختبار توكي (Tukey) للمقارنات البعدية.

4. عرض نتائج الدراسـة ومناقشتها. عرض نتائج السؤال الأول: ما مستوى الأداء التدريسي لمعلمي الرياضيات بمدارس مدينة ذمار باليمن أثناء

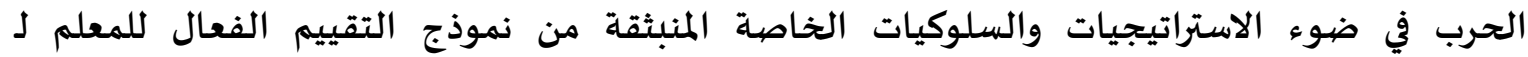

؟(Marzano)

ولإجابة عن هذا السؤال تم استخراج المتوسطات الحسابية والانحرافات المعيارية ومستوى الأداء اللفظي، وذلك على مستوى بطاقة الملاحظة ككل، وعلى مستوى كل محور من محاورها الثلاثة ومعاييرها التسعة، والجدول

الجدول (3): المتوسطات الحسابية والانحرافات المعيارية ومستوى أداء معلمي الرياضيات بمدارس مدينة ذمار باليمن.

\begin{tabular}{|c|c|c|c|c|c|}
\hline مستوى الأداء & المعياري & الحستابي & 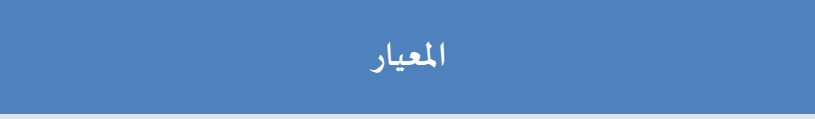 & $\hat{r}$ & 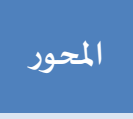 \\
\hline 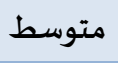 & 0.41 & 1.96 & تقديم أهداف الدرس ومتابعة أداء المتعلم والثناء على إنجازاته. & 1 & \multirow{3}{*}{ المالمحول: المهارات } \\
\hline 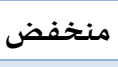 & 0.62 & 1.65 & وضع القواعد والإجراءات والحفاظ عليها. & 2 & \\
\hline متوسط & 0.46 & 1.83 & \multicolumn{2}{|l|}{ 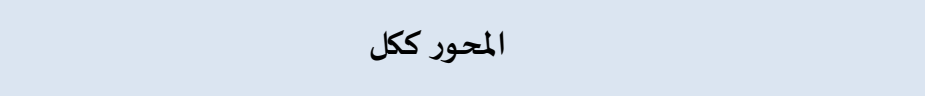 } & \\
\hline 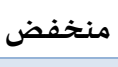 & 0.45 & 1.48 & مساعدة الطلبة على التفاعل مع المعارف الجديدة. & 3 & 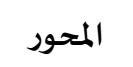 \\
\hline متوسط & 0.43 & 1.78 & مساعدة الطلبة على ممارسة المعرفة الجديدة وتعميق فهمهم لها. & 4 & 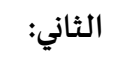 \\
\hline
\end{tabular}




\begin{tabular}{|c|c|c|c|c|c|}
\hline مستوى الأداء & الانحراف & المتوسط الحسابي & المعيار & $\hat{\imath}$ & المحور \\
\hline 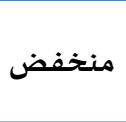 & 0.43 & 1.27 & مساعدة الطلبة على تطبيق المعرفة الجديدة من خلال إنتاج الفرضيات & 5 & \multirow{2}{*}{ المهتعلقةات } \\
\hline منخفض & 0.38 & 1.56 & \multicolumn{2}{|l|}{ 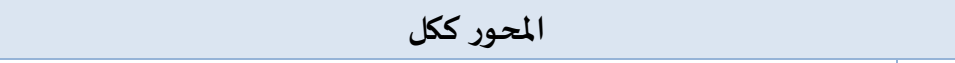 } & \\
\hline متوسط & 0.51 & 1.94 & العمل على تفعيل مشاركة الطلبة. & 6 & \multirow{5}{*}{ المالثهور المهارث: } \\
\hline متوسط & 0.56 & 2.30 & الالتزام بالقواعد والإجراءات الصفية. & 7 & \\
\hline متوسط & 0.60 & 2.20 & العمل على إنشاء علاقات فعالة مع الطلبة. & 8 & \\
\hline 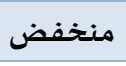 & 0.36 & 1.24 & الاهتمام بجميع فئات الطلبة من حيث الأداء. & 9 & \\
\hline متوسط & 0.46 & 1.93 & \multicolumn{2}{|l|}{ المحور ككل ل } & \\
\hline متوسط & 0.40 & 1.75 & \multicolumn{3}{|l|}{ الأداء ككل } \\
\hline
\end{tabular}

يتضح من الجدول (3) ما يأتي:

- بالنسبة لمعياري المحور الأول (المهارات الروتينية) بلغ متوسط المعيار الأول (1.96)، وبانحراف معياري (0.41)،

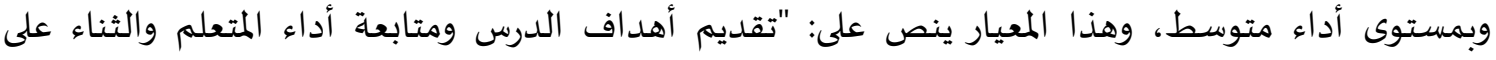

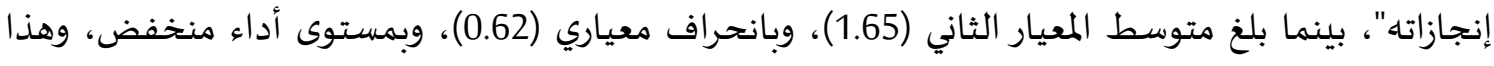

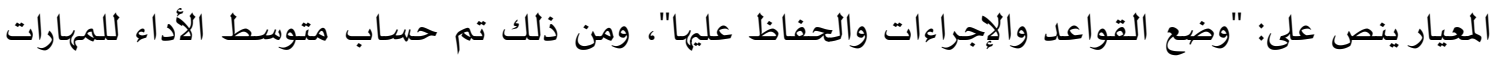

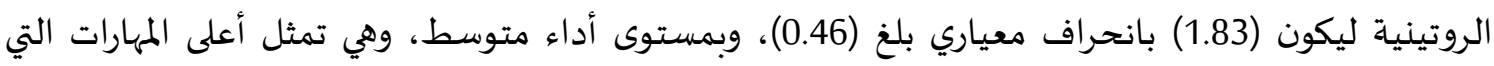

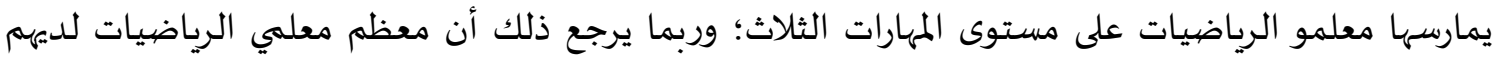

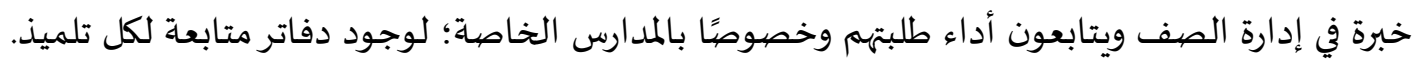

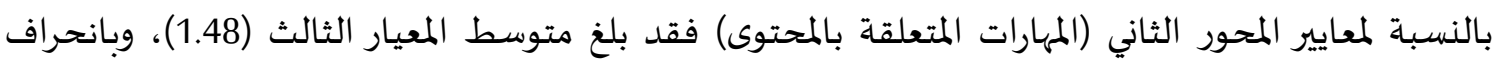

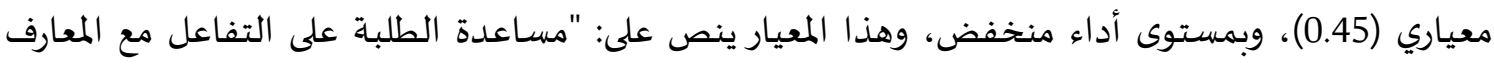

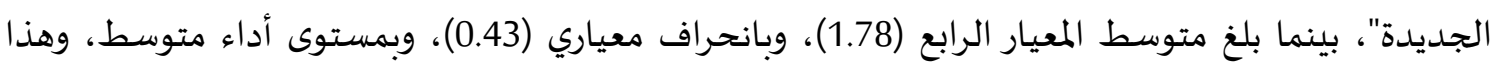

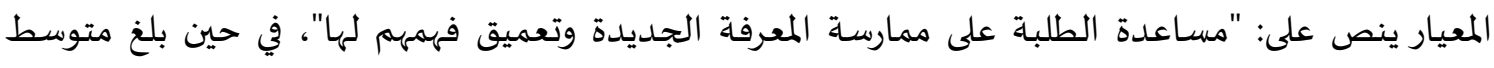

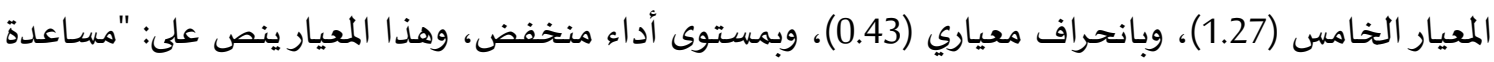

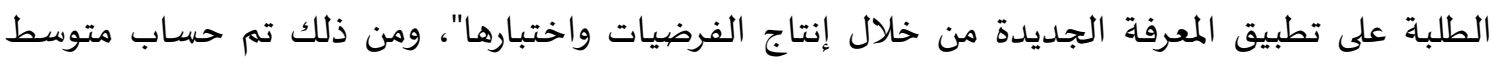

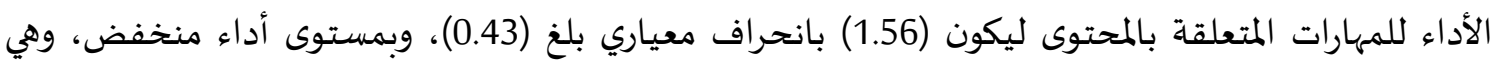

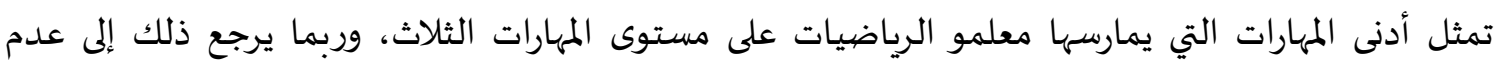

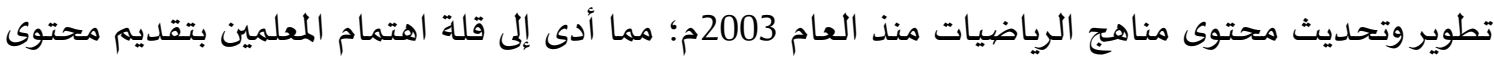
جديد لطلبتهم. بالنسبة لمعايير المحور الثالث (المهارات المتعلقة بالمحتوى) فقد بلغ متوسط المعيار السادس (1.94)، وبانحراف واف

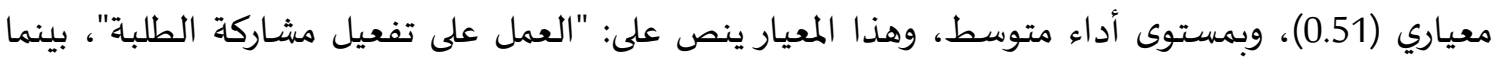

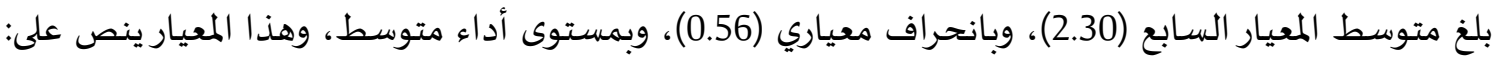

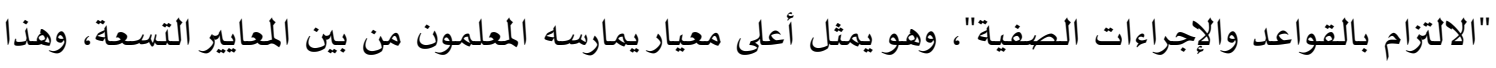

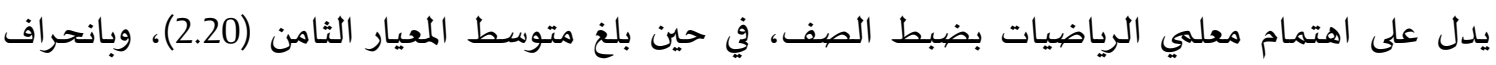

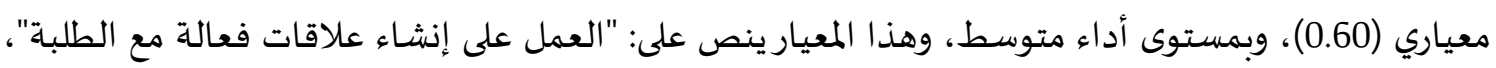

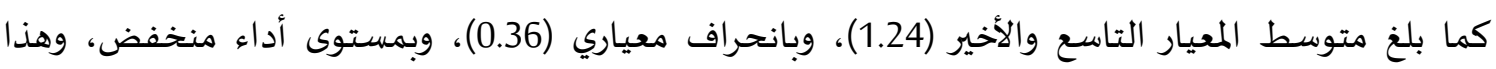


المعيار ينص على: "الاهتمام بجميع فئات الطلبة من حيث الأداء"، وهذا المعيار يمثل أدنى معيار يمارسه

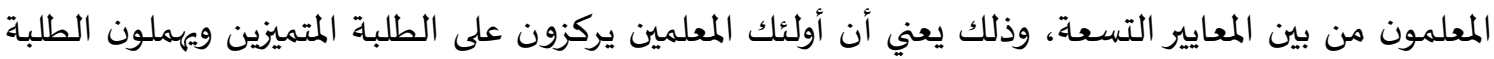

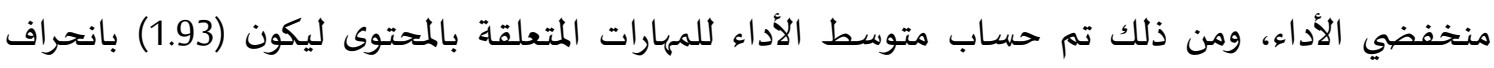

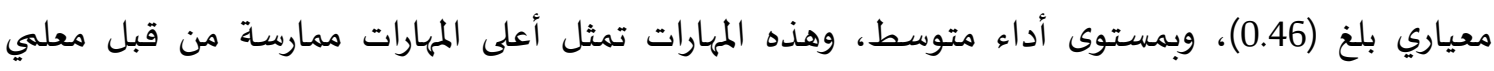

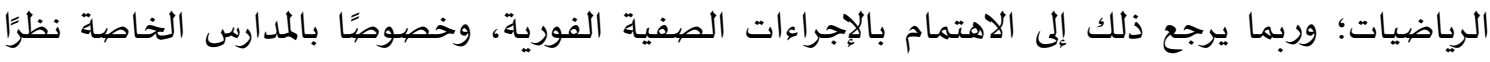

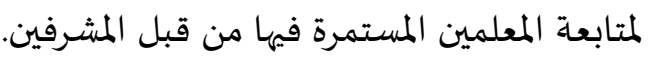
وبشكل عام فإن متوسط الأداء الكلي لمعلمي الرياضيات بمدينة ذمار بلغ (1.93) بانحراف معياري (0.46)، وبمستوى أداء متوسط، في حين تراوح متوسط محاور بطاقة الملاحظة الثلاثة (المهارات الروتينية- المهارات المتعلقة

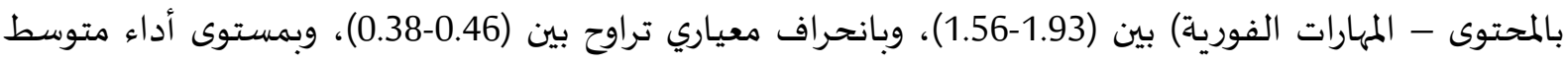

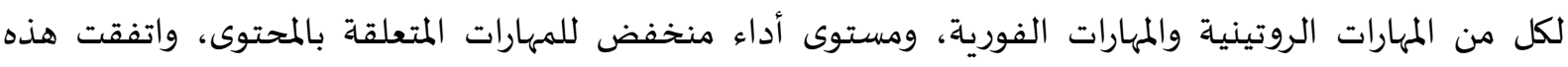

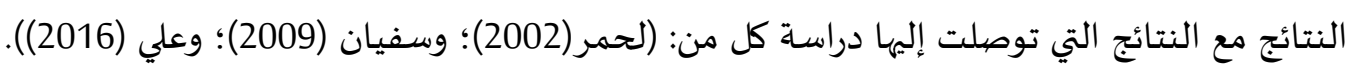

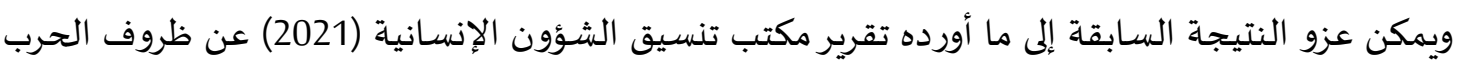

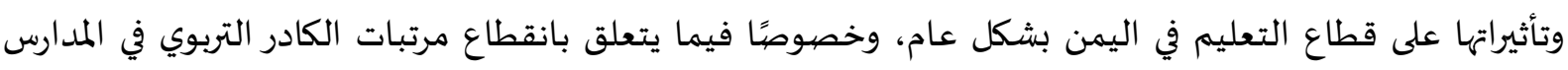

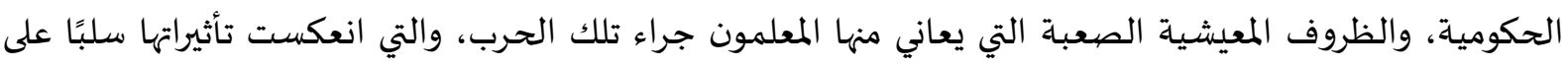
أداء المعلمين، وكذلك إيقاف التوظيف لمعلمين جدد منذ بدواية الحرب في العام 2015م، ويدعمم ذلك ما أشارت إليه دراسة الحجيلي والهدور (2019). • عرض نتائج السؤال الثاني: "ما دلالة الفروق بين معلمي الرياضيات بمدارس مدينة ذمار باليمن في مستويات الأداء التدريسي في ضوء الاستراتيجيات والسلوكيات الخاصة المنبثقة من نموذج التقييم الفعال

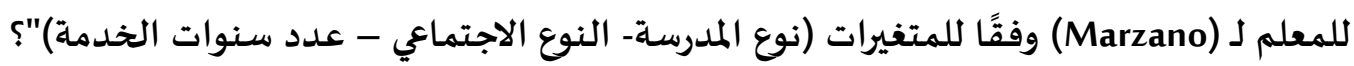

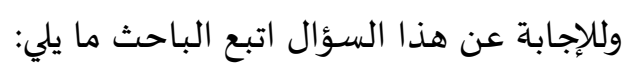

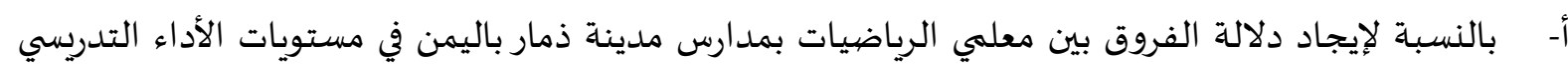

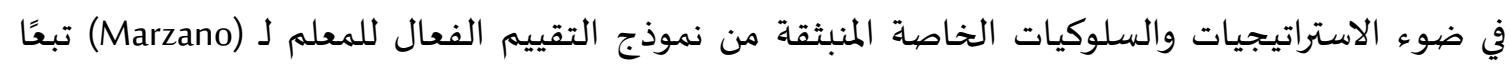

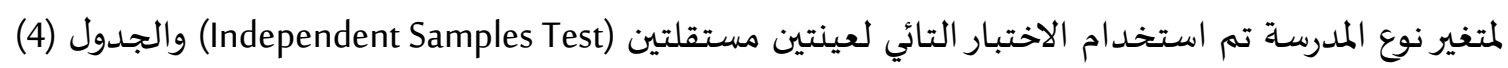
يوضح ذلك: الجدول (4): الاختبار التائي لعينتين مستقلتين لإيجاد دلالة الفروق بين معلمي الرياضيات بمدارس مدينة ذمار

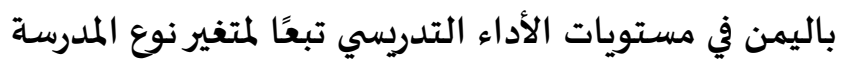

\begin{tabular}{|c|c|c|c|c|c|c|c|}
\hline مستوى الدلادة & الحرية & قيمة & الالمعياري & المتوسط & العدد & المدارس & المحور \\
\hline \multirow{2}{*}{0.00} & \multirow{2}{*}{62} & \multirow{2}{*}{7.81} & 0.36 & 2.19 & 29 & المدارس الخاصية & المححور الأول: المهارات \\
\hline & & & 0.30 & 1.54 & 35 & المدارس الحكومية & الروتينية. \\
\hline \multirow{2}{*}{0.00} & \multirow{2}{*}{62} & \multirow{2}{*}{4.81} & 0.35 & 1.78 & 29 & المدارس الخاصية & المحور الثاني: المهارات \\
\hline & & & 0.30 & 1.38 & 35 & المدارس الحكومية & المتعلقة بالمحتوى. \\
\hline \multirow{2}{*}{0.00} & \multirow{2}{*}{62} & \multirow{2}{*}{8.26} & 0.29 & 2.29 & 29 & المدارس الخاصية & المحور الثالث: المهارات \\
\hline & & & 0.35 & 1.62 & 35 & المدارس الحكومية & الفورية. \\
\hline \multirow{2}{*}{0.00} & \multirow{2}{*}{62} & \multirow{2}{*}{7.30} & 0.29 & 2.05 & 29 & المدارس الخاصة & \multirow{2}{*}{ الأداء ككل } \\
\hline & & & 0.30 & 1.51 & 35 & المدارس الحكومية & \\
\hline
\end{tabular}


يتضح من الجدول (4) أن قيمة (ت) دالة إحصائيًا على الأداء ككل وعلى مستوى المحاور الثلاثة لأن مستوى الدلالة أقل من (0.05)، وهذا يعني وجود فروق ذات دلالة إحصائية عند مستوى (0.05) في مستوى الأداء التدريسي الادي

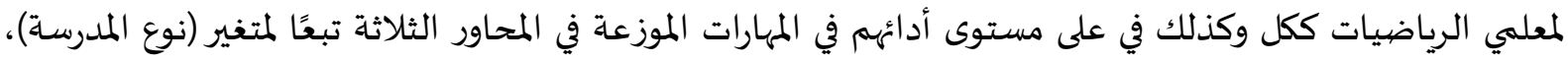

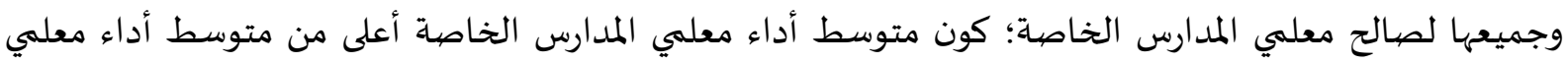

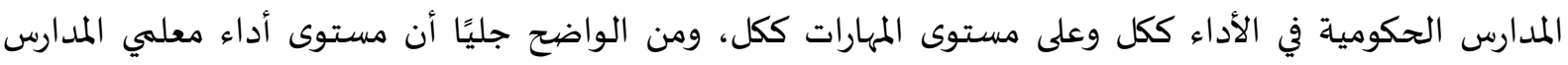

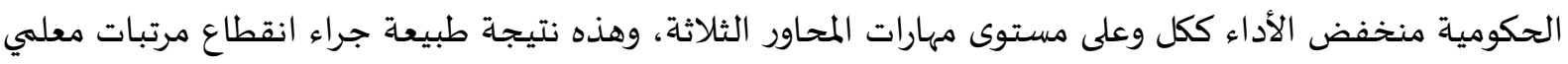

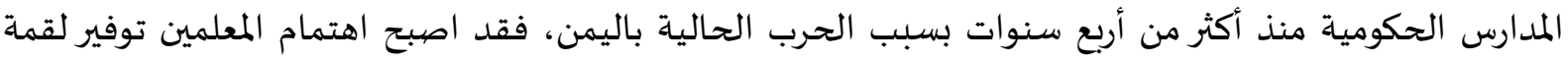

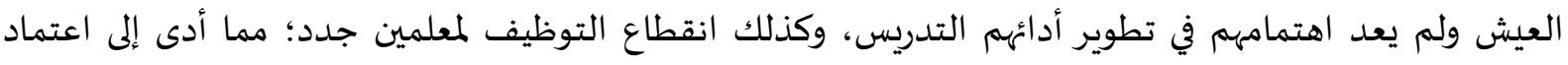

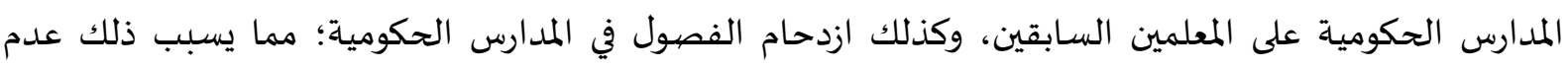

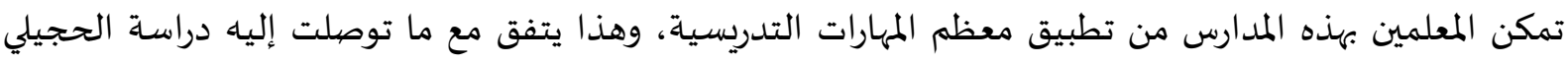
والهدور (2019)، وما أورده تقرير مكتب تنسيق الشؤون الإنسانية (2021).

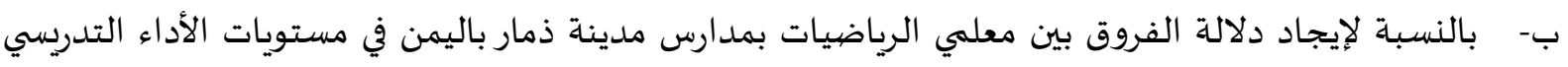

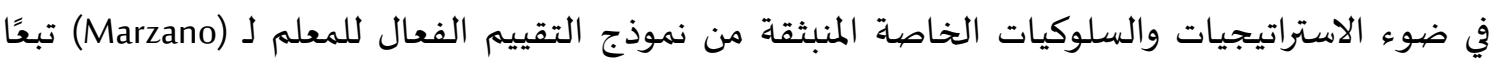
لمتغير النوع الاجتماعي للمعلمين تم استخدام الاختبار التائي لعينتين مستقلتين (Independent Samples Test)

$$
\text { والجدول (5) يوضح ذلك: }
$$

الجدول (5): الاختبار التائي لعينتين مستقلتين لإيجاد دلالة الفروق بين معلمي الرياضيات بمدارس مدينة ذمار

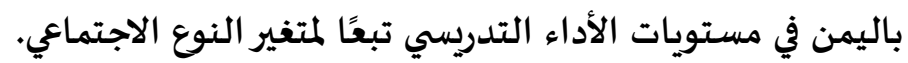

\begin{tabular}{|c|c|c|c|c|c|c|c|}
\hline 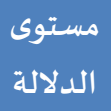 & الحرية & قيمة ت & الالمعراف & المتوسط & 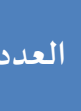 & النوع & المحور \\
\hline \multirow{2}{*}{0.00} & \multirow{2}{*}{62} & \multirow{2}{*}{-5.41} & 0.31 & 1.60 & 35 & ذكور & \multirow{2}{*}{ المحور الأول: المهارات } \\
\hline & & & 0.46 & 2.12 & 29 & إناث & \\
\hline \multirow{2}{*}{0.00} & \multirow{2}{*}{62} & \multirow{2}{*}{-5.98} & 0.21 & 1.35 & 35 & ذكور & \multirow{2}{*}{ المتحولقة بالمحتوىى. المهارات } \\
\hline & & & 0.39 & 1.81 & 29 & إناث & \\
\hline \multirow{2}{*}{0.00} & \multirow{2}{*}{62} & \multirow{2}{*}{-7.27} & 0.32 & 1.64 & 35 & ذكور & \multirow{2}{*}{ المحور الثالث: المهارات } \\
\hline & & & 0.37 & 2.27 & 29 & إناث & \\
\hline \multirow{2}{*}{0.00} & \multirow{2}{*}{62} & \multirow{2}{*}{-7.15} & 0.24 & 1.51 & 35 & ذكور & \multirow{2}{*}{ الأداء ككل } \\
\hline & & & 0.36 & 2.05 & 29 & إناث & \\
\hline
\end{tabular}

يتضح من الجدول (5) أن قيمة (ت) دالة إحصائيًا على الأداء ككل وعلى مستوى المحاور الثلاثة؛ لأن مستوى الدلالة أقل من (0.05)، وهذا يعني وجود فروق ذات دلالة إلة إحصائية عند مستوى (0.05) في مستوى الأداء

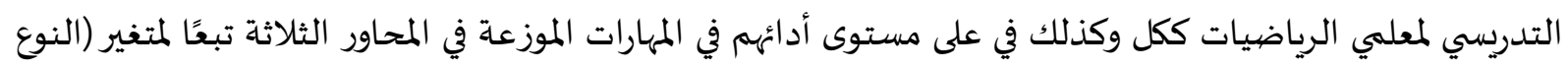

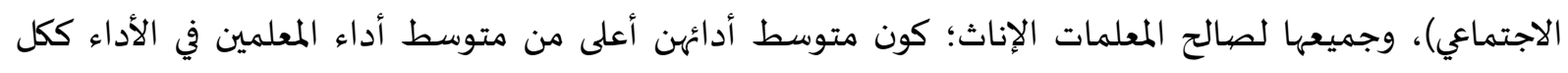

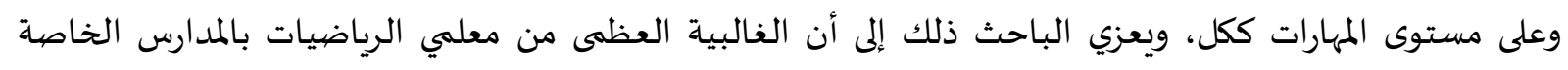

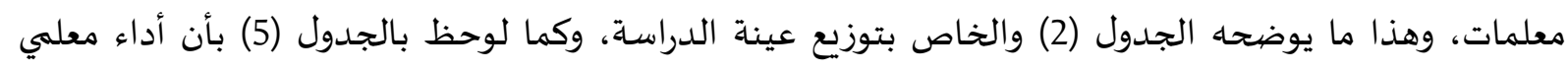
المدارس الخاصة أفضل من أداء معلمي المدارس الحكومية، وربما يعزى ذلك أيضًا إلى أن المعلمين الذكور لديها بلهيه 
التزامات أخرى لتوفير لقمة العيش؛ نظرًا لانقطاع صرف المرتبات بالمدارس الحكومية منذ أكثر من اربع سنوات

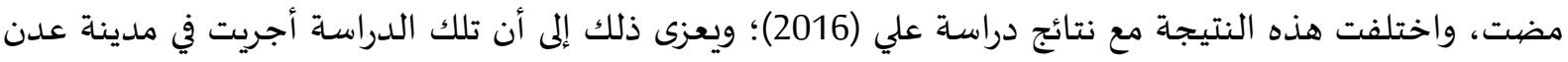
وطبقت بالعام 2014/2013 قبل بداية الحرب. ج- ولإيجاد دلالة الفروق بين معلمي الرياضيات بمدارس مدينة ذمار باليمن في مستويات الأداء التدربسي في ضوء

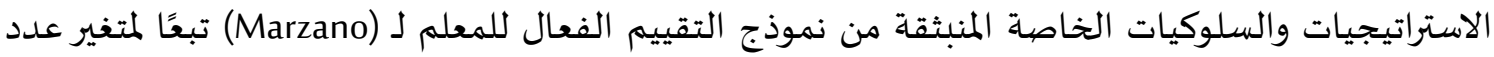

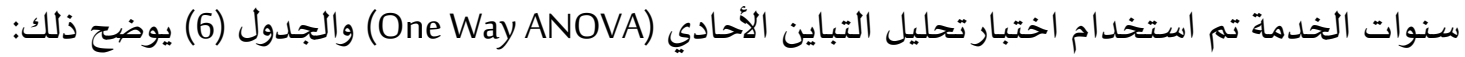

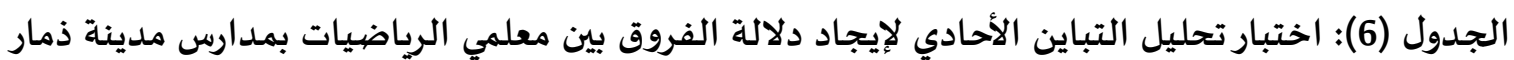

باليمن في مستويات الأداء التدريسي تبعًا لمتغير عدد سنوات الخدمة.

\begin{tabular}{|c|c|c|c|c|c|c|}
\hline مستوى الدلالة & 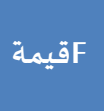 & المربعات & الحرية & المجربعات & مصددر التباين & 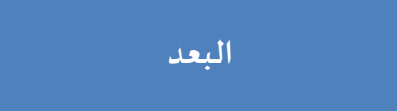 \\
\hline \multirow[t]{3}{*}{0.00} & 15.65 & 2.25 & 2 & 4.49 & بين المجموعات & \multirow{3}{*}{ المحور الأول: المهارات الروتينية. } \\
\hline & & 0.14 & 61 & 8.75 & داخل المجموعات & \\
\hline & & & 63 & 13.24 & المجموع & \\
\hline \multirow[t]{3}{*}{0.00} & 14.55 & 1.47 & 2 & 2.94 & بين المجموعات & \multirow{3}{*}{ المحتور الثاني: المهارات المتعلقة } \\
\hline & & 0.10 & 61 & 6.16 & داخل المجموعات & \\
\hline & & & 63 & 9.09 & المجموع & \\
\hline \multirow[t]{3}{*}{0.00} & 17.15 & 2.43 & 2 & 4.86 & بين المجموعات & \multirow{3}{*}{ المحور الثالث: المهارات الفورية. } \\
\hline & & 0.14 & 61 & 8.63 & داخل المجموعات & \\
\hline & & & 63 & 13.49 & 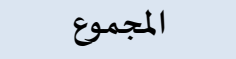 & \\
\hline \multirow[t]{3}{*}{0.00} & 18.60 & 1.93 & 2 & 3.86 & بين المجموعات & \multirow{3}{*}{ الأداء ككل } \\
\hline & & 0.10 & 61 & 6.33 & داخل المجموعات & \\
\hline & & & 63 & 10.19 & المجموع & \\
\hline
\end{tabular}

يتضح من الجدول (6) أن قيمة (F) دالة إحصائيًا على الأداء ككل وعلى مستوى المحاور الثلاثة لأن مستوى

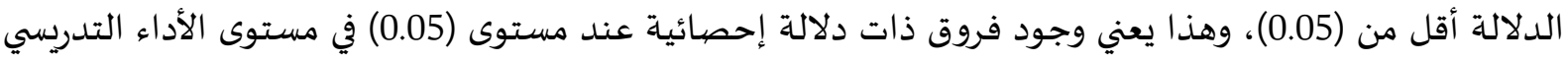

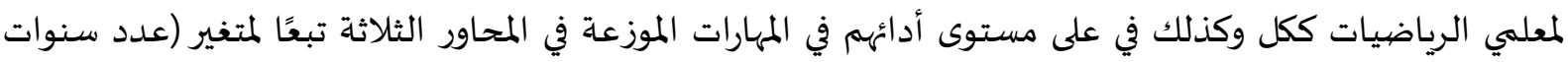
الخدمة)، وللتعرف على مصادر تلك الفروق بين فئات سنوات الخدمة المختلفة للمعلمين أفراد العينة تم ايجاد الأوساط الحسابية والانحرافات المعيارية لكل فئة، ثم المقارنة بينهما باستخدام اختبار توكي (Tukey) للمقارنات البعدية، والجدول (7) يوضح نتائج ذلك: الكبان: الجدول (7): اختبار (Tukey) للمقارنات البعدية لإيجاد الفروق في مستوى معلمي الرياضيات أفراد العينة تبعًا لمتغير عدد سـنوات الخدمة.

\begin{tabular}{|c|c|c|c|c|c|c|}
\hline سنو أكن من (10) & سنوات & الانعراف & المتوسط & العدد & التخصص & البعد \\
\hline $0.51^{*}$ & -0.03 & 0.39 & 2.08 & 16 & أقل من (5) سـنوات & \multirow{3}{*}{ المحور الأول: المهارات } \\
\hline \multirow[t]{2}{*}{$0.54^{*}$} & & 0.42 & 2.11 & 17 & (5-10)سنوات & \\
\hline & & 0.35 & 1.56 & 31 & أكثر من (10) سنوات & \\
\hline
\end{tabular}


المجلة العربية للعلوم ونشر الأبحاث ـ مجلة الطوم التربوية والنفسية ـ المجلد الخامس ـ العدد الثاني والأربعون ـ نوفمبر 2021م

\begin{tabular}{|c|c|c|c|c|c|c|}
\hline سأكثر من (10) & سنوات & الانحراف & المتوسط & العدد & التخصص & البعد \\
\hline $0.29^{*}$ & -0.21 & 0.36 & 1.65 & 16 & أقل من (5) سـنوات & \multirow{3}{*}{ المتحولقة بالمحتوى المهارات } \\
\hline \multirow[t]{2}{*}{$0.50^{*}$} & & 0.34 & 1.86 & 17 & (10-5) سنوات & \\
\hline & & 0.29 & 1.35 & 31 & أكثر من (10) سنوات & \\
\hline $0.49^{*}$ & -0.11 & 0.34 & 2.13 & 16 & أقل من (5) سنوات & \multirow{3}{*}{ المحور الثالث: المهارات } \\
\hline \multirow[t]{2}{*}{$0.60^{*}$} & & 0.36 & 2.25 & 17 & (10-5) سنوات & \\
\hline & & 0.40 & 1.65 & 31 & أكثر من (10) سنوات & \\
\hline $0.40^{*}$ & -0.15 & 0.32 & 1.91 & 16 & أقل من (5) سنوات & \multirow{3}{*}{ الأداء ككل } \\
\hline \multirow[t]{2}{*}{$0.550^{*}$} & & 0.32 & 2.06 & 17 & (10-5) سنوات & \\
\hline & & 0.33 & 1.51 & 31 & أكثر من (10) سنوات & \\
\hline
\end{tabular}

* دال إحصائيًا عند مستوى دلالة (0.05).

من الجدول (7) يتضح بأن الفروق الدالة إحصائيًا عند مستوى (0.05) بين المعلمين ذوي فئتي سنوات الخدمة أقل من (5) سنوات من جهة وأكثر من (10) سنوات من جهة أخرى، وبالرجوع إلى المتوسطات نجد أندات أن تلك

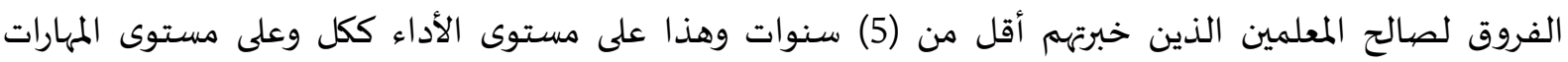
الموزعة بالمحاور الثلاثة على حدة، وكذلك يتبين وجود فروق ذات دلالة إحصائية عند مستوى (0.05) بين المعلمين

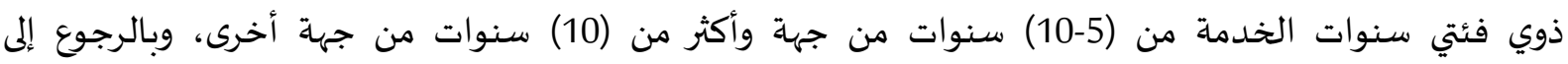

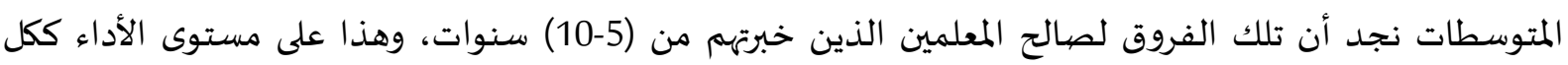

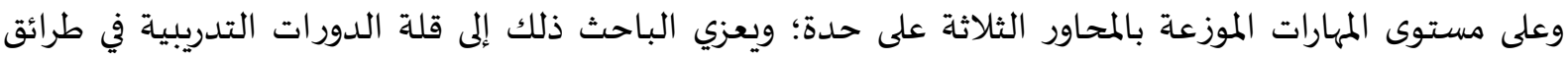

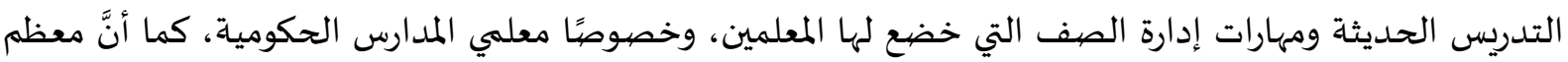

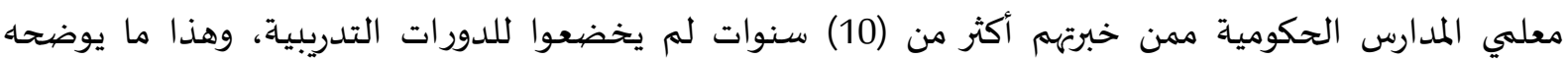
الجدول (2) والخاص بتوزيع عينة الدراسة، وهذا ما توصلت إليه نتائج دراسة غليون وأبو صليط (2016)، بينما غالبية معلمي المدارس الخاصة ممن خبرتهم أقل من (10) سنوات؛ وتولي المدارس الخاصية اهتمامها بإجراء دورات

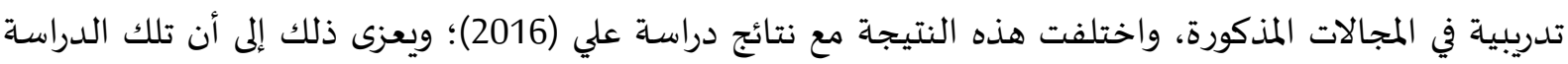

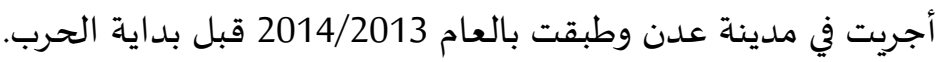

\section{التوصيات والمقترحات.}

في ضوء النتائج التي تم التوصل الحالية، يوصي الباحث ويقترح بما يأتي:

1- إجراء دورات تنمية مهنية لمعلمي الرياضيات بمدينة ذمار حول التدريس الفعال ومهارات إدارة الصف.

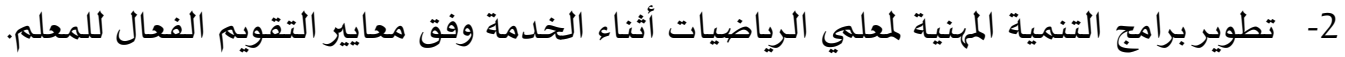

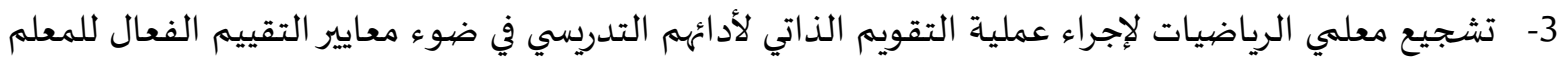

لتحسين مستواهم.

4- ت تحييد المؤسسات التعليمية عن الحرب وصرف مستوافم مرتبات المعلمين. 5- واستكمالًا لهذه الدراسة يقترح الباحث إجراء دراسات على التعات النحو الآتي:

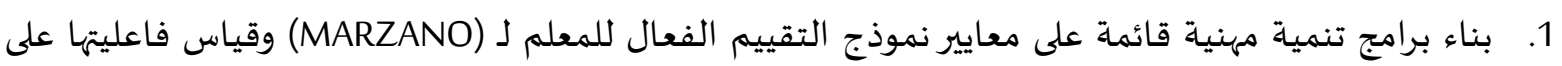
أداء المعلمين. 
2. تقييم أداء معلمي الرياضيات في ضوء نموذج التقييم الفعال للمعلم لـ (MARZANO) في بقية المحافظات اليمنية. 3. تقييم أداء معلمي المواد الدراسية الأخرى في ضوء نموذج التقييم الفعال للمعلم لـ (MARZANO) في بقية المحافظات اليمنية.

قائمة المراجع.

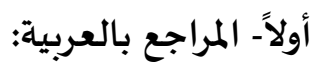
- إبراهيم، مجدي عزيز. (2009). معجم مصطلحات ومفاهيم التعليم والتعلم. القاهرة: عالم الكتب. - أحمد، صفاء محمد. (2016). فاعلية برنامج قائم على نموذج (Marzano) لتقييم المعلم في تنمية مهارات التدريس لدى الطلبة معلمي اللغة العربية وتحسين تصوراتهم عن فاعلية أدائهم. مجلة القراءة والمعرفة - كلية

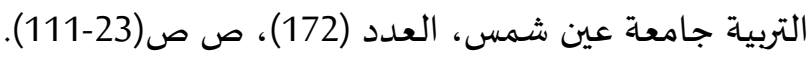
الأحمري، صالح عائض؛ والصمداني، هاشم. (2019). بطاقة مقترحة لتقويم أداء معلم اللغة الإنجليزية في ضوء صاء

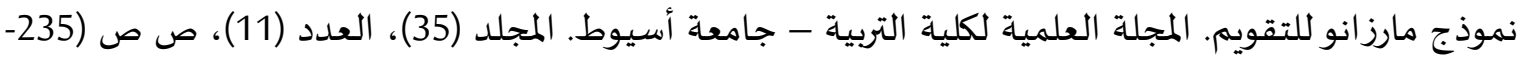
(276 - الحجيلي، نصر؛ والهدور، زيد. (2019). تحقق معايير الحد الأدنى للتعليم في حالات الطوارئ (INEE) أثناء فترة

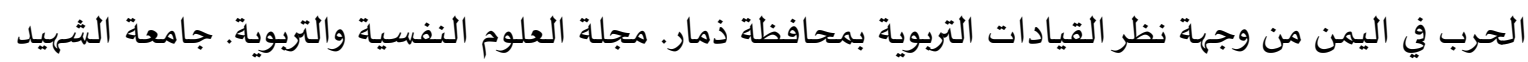

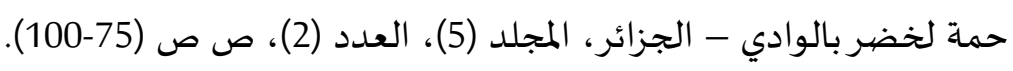

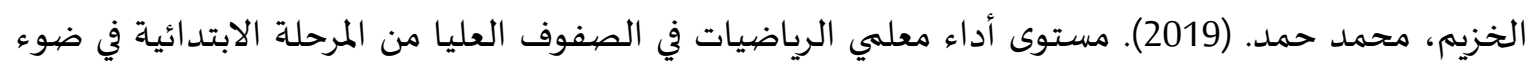

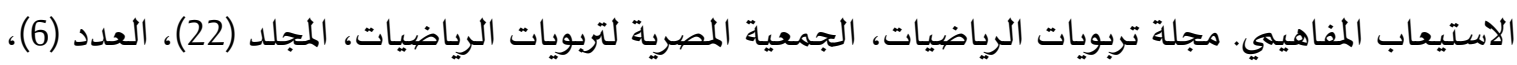
الجزء (3)، ص ص (157-177). السعيد، إسلام محمد. (2020). برامج التنمية الهنية للمعلم في بيئات الطوارئ، مجلة آفاق جديدة في تعليم

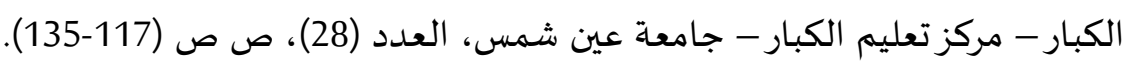

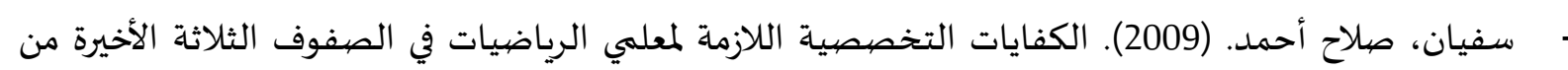

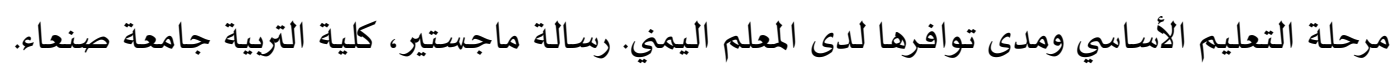

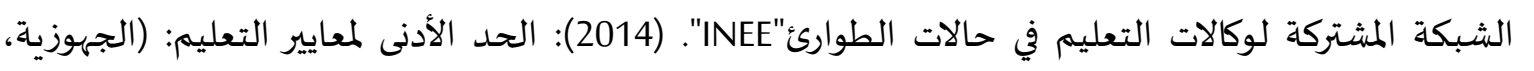
الاستجاباة، التعافي). نيويورك: اليونسيف. لوكات التعليف - شحاته، حسن؛ والنجار، زينب. (2003). معجم المصطلحات التربوية والنفسية. الدار المصرية اللبنانية: القاهرة.

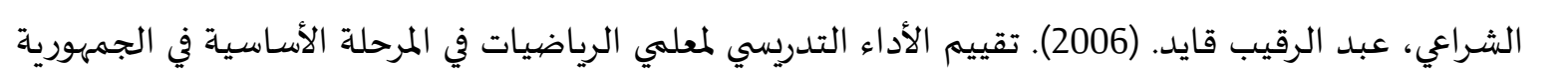
اليمنية، رسالة ماجستير، جامعة إب. عابد الئ.

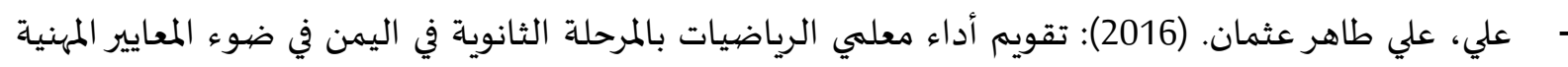

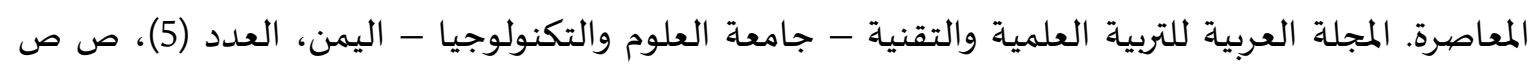


- الغامدي، عايض؛ والجعفري، علي. (2020). مدى توفر المعايير المهنية (NCTM) في أداء معلمي الرياضيات

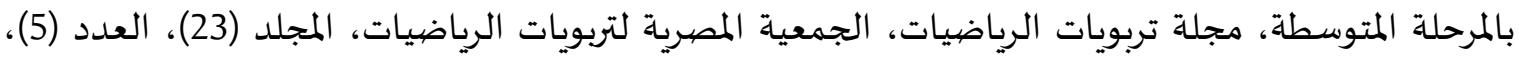
الجزء (1)، ص ص (177-203).

- غليون، أزهار؛ وأبو صليط، عبد الله. (2016). الوضع الراهن والتحديات التي تواجهها برامج التنمية المهنية للمعلمين باليمن. مجلة أبحاث - كلية التربية بجامعة الحديدة، العدد (5)، ص ص صاندان (1-30).

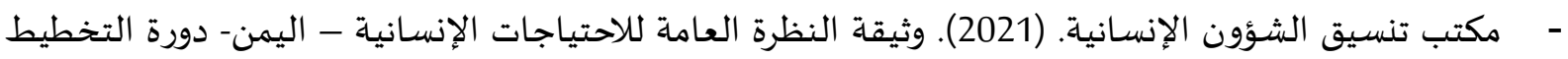
للبرامج الإنسانية. الأمم المتحدة: OCHA.

\section{ثانياً- المراجع بالإنجليزية:}

- Carbaugh, B., Marzano, R.\& Toth, M. (2017). New to the Marzano Teacher Evalution Model? The Marzano Focused Teacher Evaluation Model. A Focused, Scientific-Behavioral Evaluation Model for Standards-Based Classrooms. West Palm Beach, FL: Learning Sciences Marzano Center.

- Cooper, J. (1974). Measurement \& Analysis of Behavior Techniques. Ohio: C. E. Merrill Pub. Co.

- Eller, J. F., \& Eller, S. A. (2015). Score to soar: Moving teachers from evaluation to professional growth. Solution Tree Press.

- Graziano, K. S. (2016). An Exploration of Teacher Perception of the Marzano Causal Teacher Evaluation Model and Its Impact on Professional Practices. PhD Thesis, Seton Hall University, USA.

- Hoge, M. H. (2016). The Relationship between Teachers' Instructional Practices, Professional Development, and Student Achievement. PhD Thesis, University of Nebraska, USA.

- Holsti, O. (1969). Content analysis for the social science and humanities. Canada: Wesley Company.

- Learning Sciences Marzano Center. (2013). Developing a Passion for Professional Teaching: The Marzano Teacher Evaluation Model. Learning Sciences International. https://www.learningsciences.com/wp-content/uploads/2020/06/The-Marzano-TeacherEvaluation-Model.pdf

- Marchant, G. J., David, K. A., Rodgers, D., \& German, R. L. (2015). State teacher evaluation and teacher education. The Teacher Educator, 50(2), 89-108.

- Marzano, R. G., Carbaugh, B., Rutherford, A. \& Toth, M. (2014). Marzano Center Teacher Observation Protocol for the 2014 Marzano Teacher Evaluation Model. West Palm Beach, FL: Learning Sciences Marzano Center.

- Marzano, R. J. \& Toth, M. D. (2013). Teacher evaluation that makes a difference: A new model for teacher growth and student achievement. Alexandria, Virginia: ASCD.

- Marzano, R. J. \& Toth, M. D. (2014). Teaching for Rigor: A Call for a Critical Instructional Shift, why essential shifts in instruction are necessary for teachers and students to succeed with college and career readiness standards. West Palm Beach, FL: Learning Sciences Marzano Center. 
- Smith, M. A. (2018). Teacher Evaluation Practices That Promote Teacher Development in Two Middle Schools. PhD Thesis, University of Northern Colorado, USA.

- Tetzlaff, T. (2018). Teacher Evaluation-Study of Minnesota Secondary School Principals Related to the Amount of Time Necessary to Implement Common Teacher Evaluation Models. PhD Thesis, St. Cloud State University, USA. 